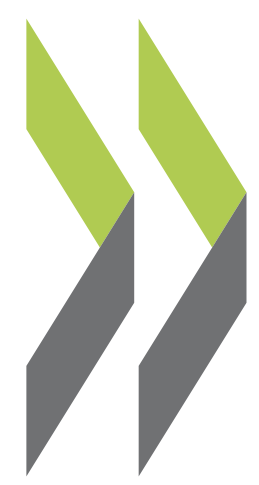

OECD Economics Department Working Papers No. 370

The Retirement Effects of Old-Age Pension and Early Retirement Romain Duval Schemes in OECD Countries 
ECONOMICS DEPARTMENT

THE RETIREMENT EFFECTS OF OLD-AGE PENSION AND EARLY RETIREMENT SCHEMES IN OECD COUNTRIES

ECONOMICS DEPARTMENT WORKING PAPERS NO.370

By Romain Duval

All Economics Department Working Papers are now available through the OECD Internet website at http://www.oecd.org/eco 


\section{ABSTRACT/RESUMÉ}

\section{The retirement effects of old-age pension systems and other social transfer programmes in OECD countries}

This paper examines the impact of old-age pension systems and other social transfer programmes on the retirement decision of older males in OECD countries. For each of the 55-59, 60-64 and 65+ age groups, a new panel dataset (22 OECD countries over 1969-1999 or shorter periods in some cases) of retirement incentives embedded in those schemes is constructed for an illustrative worker. The main focus is on the implicit tax rate on working for five more years, which sums up various dimensions of retirement incentives such as the pension accrual rate but also, to a lesser extent, the availability and generosity of benefits. There is currently wide dispersion across OECD countries in implicit tax rates on continued work embedded in old-age pension and early retirement schemes: they are high in most Continental European Countries, compared with Japan, Korea, English-speaking and Nordic countries. Simple cross-country correlations and panel data econometric estimates both show that implicit taxes on continued work have sizeable effects on the departure of older male workers from the labour force. For the 55-59 age group, there is clear evidence that these effects result from a number of social transfer programmes, which have been used de facto as early retirement schemes, rather than from old-age pension systems themselves. For the 60-64 and 65+ age groups, eligibility ages also appear to have a specific impact on the retirement decision, probably reflecting liquidity and/or customary effects.

JEL Classification: H55, J14, J21, J26

Key words: Social Security, public pensions, economics of the elderly, labor force and employment, retirement policies

\section{L'impact des systèmes de retraite et d'autres programmes de transferts sociaux sur la décision de départ à la retraite dans les pays de l'OCDE}

Cet article examine l'impact des systèmes de retraite et d'autres programmes de transferts sociaux sur la décision de départ à la retraite des hommes âgés dans les pays de l'OCDE. Pour chacun des groupes d'âge 55-59, 60-64 et 65+, un nouveau panel (22 pays de l'OCDE sur 1969-1999 ou des périodes plus courtes dans certains cas) de données concernant les incitations au départ à la retraite est construit pour un travailleur illustratif. L'analyse se concentre principalement sur la taxe implicite sur la poursuite du travail pour cinq années supplémentaires, qui synthétise différentes dimensions des incitations au départ à la retraite telles que le taux d'accumulation des droits à pension mais aussi, dans une moindre mesure, la disponibilité et la générosité des prestations. Il existe actuellement entre pays de l'OCDE une importante dispersion des taxes implicites sur la poursuite du travail engendrées par les systèmes de retraite et de préretraite : elles sont élevées dans la plupart des pays d'Europe continentale, comparativement au Japon, à la Corée, aux pays de langue anglaise et aux pays nordiques. Des corrélations simples et des estimations économétriques sur données de panel montrent toutes deux que les taxes implicites sur la poursuite du travail ont des effets conséquents sur le retrait des hommes âgés du marché du travail. Pour le groupe d'âge 55-59, il ressort clairement que ces effets résultent d'un certain nombre de programmes de transferts sociaux, qui ont été utilisés de facto comme des systèmes de préretraite, plutôt que des systèmes de retraite eux-mêmes. Pour les groupes d'âge 60-64 et 65+, les âges d'éligibilité apparaissent également exercer un 
impact spécifique sur la décision de départ à la retraite, reflétant probablement des effets de liquidité et/ou d'usage.

Classification JEL : H55, J14, J21, J26

Mots Clés: Systèmes de retraite, retraites publiques, économie du vieillissement, population active et emploi, politiques de retraite

Applications for permission to reproduce or translate all, or part of, this material should be made to : Head of Publications Service, OECD, 2 rue André-Pascal, 75775 Paris Cedex 16, France. 


\section{TABLE OF CONTENTS}

\section{THE RETIREMENT EFFECTS OF OLD-AGE PENSION AND EARLY RETIREMENT SCHEMES IN

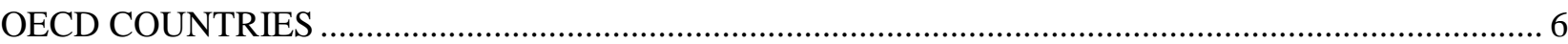

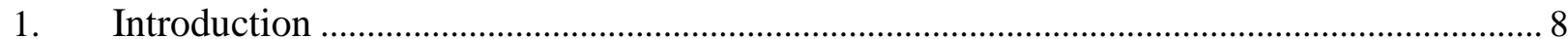

2. Early retirement incentives embedded in old-age pension systems and other social transfer

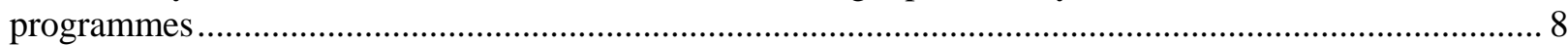

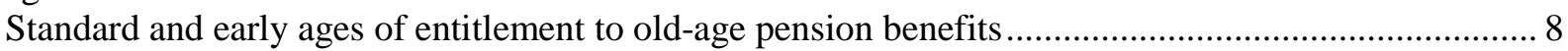

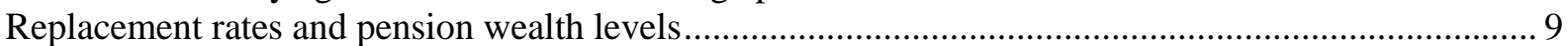

Implicit marginal taxes on continued work in old-age pension systems ........................................... 13

Implicit marginal taxes on continued work in early retirement schemes ............................................ 14

3. Effects of implicit tax rates on labour market participation of older workers: preliminary cross-

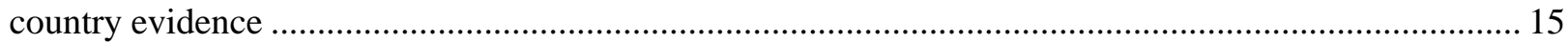

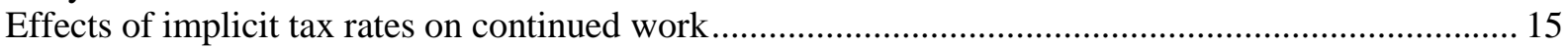

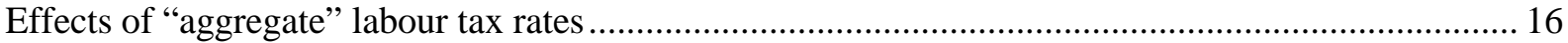

4. Panel data econometric analysis of determinants of the labour force participation of older workers 17

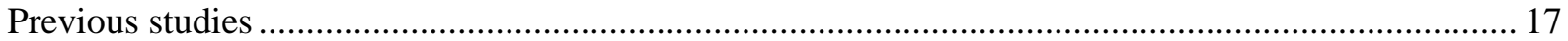

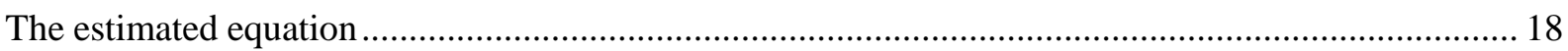

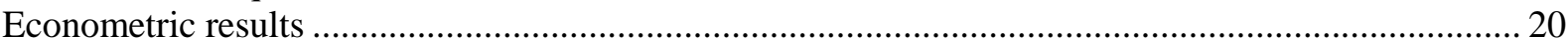

5. Policies to increase labour market participation of older workers ............................................. 22

Appendix 1: Computing replacement rates in old-age pension systems and early retirement schemes:

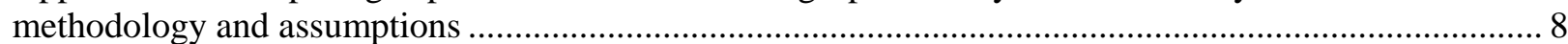
Appendix 2: Computing pension, social wealth and implicit taxes on continued work: methodology and

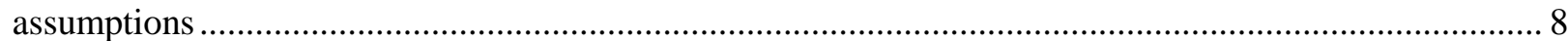

Appendix 3: Ongoing and already decided pension reforms .......................................................... 8

Appendix 4: Theoretical relationship between replacement rates and implicit taxes on continued work .. 8

Appendix 5: An overview of the "option value" model of the retirement decision ................................... 8

\section{Boxes}

1. The gains from moving towards actuarially neutral pension systems

2. A brief overview of the datasets on retirement incentives available at the OECD

Tables

1. Standard and early ages of entitlement to old-age pension benefits

2. Panel data estimates of the labour force participation of older workers

\section{Figures}

1. Labour force participation of older workers and estimated effective retirement age in 2000 
2. Average expected replacement rates over next 5 years in current old-age pension systems, average across 6 situations ( 3 earnings levels and 2 marital statuses)

3. Historical changes in average expected replacement rates in old-age pension systems, average across 6 situations ( 3 earnings levels and 2 marital statuses)

4. Average implicit tax rates on continued work over next 5 years in current old-age pension systems, single worker with average production worker (APW) earnings

5. Average expected replacement rates and implicit tax rates on continued work in current old-age pension systems

6. Historical changes in average implicit tax rates on continued work in old-age pension systems, single worker with APW earnings

7. Fall in male labour force participation between 50-54 and 55-59 and implicit tax rates on continued work (single worker APW earnings, 1999)

8. Fall in male labour force participation between 55-59 and 60-64 and implicit tax rates on continued work (single worker APW earnings, 1999) 


\title{
THE RETIREMENT EFFECTS OF OLD-AGE PENSION AND EARLY RETIREMENT SCHEMES IN OECD COUNTRIES
}

\author{
By
}

\author{
Romain Duval $^{1}$
}

\section{Introduction}

1. Over the future decades, population ageing will induce a substantial "greying" of the workingage population in OECD countries. Given their currently low labour market attachment compared with prime-age workers, aggregate participation and employment rates would decline and old-age dependency ratios would rise (Burniaux et al., 2003). These evolutions, combined with the growth slowdown associated with lower growth rates of the working-age population, would put increasing pressure on living standards and the fiscal sustainability of social expenditures. Increasing the labour force participation and employment of older workers, not least by raising average effective retirement ages (Figure 1 ) ${ }^{2}$ could help alleviate the burden of ageing populations by curbing the rise in age-related spending while at the same time generating higher tax revenues to finance it. ${ }^{3}$ It has also been argued that higher participation rates of older workers would be welfare-enhancing in many OECD countries, on both theoretical (Box 1) and empirical grounds.

[Figure 1. Labour force participation of older workers and effective retirement age in 2000]

1. Romain Duval is an economist in the Structural Policy analysis Division of the OECD Economics Department. The author would like to thank Jean-Marc Burniaux, Florence Jaumotte, Willi Leibfritz, Svenbjörn Blöndal, Jorgen Elmeskov, Mike Feiner and other colleagues in the OECD Economics Department for their valuable comments. Invaluable statistical assistance was provided by Catherine Chapuis-Grabiner.

2. In principle, there is no straightforward relationship between the effective retirement age and the labour force participation of older workers. For instance, even if participation is higher in a country than another, the effective retirement age may still be lower if labour market participants withdraw earlier. However, as shown in Figure 1, there is actually a very strong cross-country relationship between both variables: countries with lower participation rates of older workers tend to have lower effective retirement ages. Therefore, increasing the effective retirement age and raising the labour force participation of older workers appear to go hand in hand in practice.

For instance, under a set of simplifying assumptions, among which the potential participation rate of the 55-64 age group is equal to that of the 25-54 age group, Herbertsson and Orszag (2003) estimate that the loss of output which can be attributed to early retirement was equal to seven per cent of GDP on average in the OECD area in 2001. There were wide differences across countries, with the output cost ranging from 1.6 per cent of GDP in Iceland to as high as 16.5 per cent in Hungary. Under the assumption that the potential participation rate of the 55-64 age group is ten per cent below rather than equal to that of the 2554 age group, these output cost estimates decrease by 25 per cent on average, but still remain large. 
2. Effective retirement ages have declined trend-wise in most countries, at least until recent years when they stabilised or reversed slightly in some cases, and cross-country differences widened (Burniaux et al., 2003). These trends may be accounted for by a broad range of factors. Some of these directly reduce labour supply, such as wealth effects associated with rising living standards, increased demand for leisure, and policies that distort retirement incentives, including through the design of welfare systems. Other factors affect supply indirectly via reduced labour demand, such as: i) declining relative productivity and wages of low-skilled older workers in times of rapid technological change (Perrachi and Welch, 1994; Lee, 2003); ii) limited training, leading to low earnings capacity; and, iii) temporary negative demand shocks leading to irreversible labour force withdrawal. Rigid age-earnings profiles, supported by specific institutional arrangements (e.g. high minimum wage, stringent employment protection legislation, high replacement income) affect supply directly but also reduce labour demand with indirect repercussions on supply. Some of these influences interact with each other. For instance, rigid age-earnings profiles may provide insufficient incentives to engage in training to improve skills.

\section{Box 1. The gains from moving towards actuarially neutral pension systems}

Beyond the need to ensure the long-run financial viability of old-age pension systems, economic theory suggests under the most general conditions that moving towards more actuarial neutrality would improve welfare (see for instance Blanchet et al., 1996). ${ }^{1}$ Indeed, since retirement benefits must be financed through taxes, early labour market withdrawal comes at the expense of living standards over the life cycle. Actuarially non-neutral retirement schemes tend to bias the retirement decision towards excessive leisure and insufficient consumption, thereby reducing welfare.

They also raise other concerns which go beyond the scope of this paper. In particular, the design of most current Pay-As-You-Go (PAYG) schemes is not well-adapted to ongoing socioeconomic changes, such as increasing female labour force participation ceilings and tapers for joint pensions exist in many countries, the rise in atypical forms of employment or the need for lifelong learning and labour mobility across countries (especially in Europe: Holzmann et al., 2003). Stricter contribution-benefit relationships at the individual - rather than couple level would be a step towards solving these issues

One argument sometimes raised against actuarially neutral pension systems is the fact that they prevent any redistribution of income within generations, ${ }^{2}$ which was a secondary goal of Pay-As-You-Go (PAYG) schemes at the time of their creation. However, existing PAYG systems do not generally redistribute income from high-wage to lowwage earners, mainly because higher replacement rates offered to the latter do not, in practice, compensate for their significantly lower life expectancy (Lindbeck and Persson, 2003). Furthermore, to a certain extent an actuarially neutral system can always be complemented by transfers aimed at redistributing income towards workers with low-wage histories and/or incomplete careers.

1. Moving to exact actuarial neutrality (ex ante) for all individuals would, however, prove difficult in practice. The main reason is that life expectancy differs across various population groups (males and females, blue collar and white collar workers...).

2. They may even be anti-redistributive if the existing difference in life expectancy between high and low- income earners is not taken into account in the pension benefit formula.

3. This paper examines the impact of early retirement incentives embedded in pension systems and other social transfer programmes on the labour force participation of older workers. This relatively narrow focus on social protection systems is adopted for various reasons. First, in reasonably well-functioning labour and product markets, supply-side factors are major long-run determinants of labour force participation, even though in practice market imperfections also assign an influential role to demand-side factors. In this paper, a range of labour-market policies and regulations, such as tax wedges, minimum wages, employment protection legislation or active labour market policies, are indirectly taken into 
account to the extent that they affect labour force participation indirectly via their impact on unemployment ("discouraged worker" effect) but not explicitly explored. ${ }^{4}$ Second, reducing early retirement incentives may to a certain extent contribute to easing labour demand constraints, for example by lengthening the pay-back period for investment in training. They may also reduce the risk that temporary negative demand shocks induce some older workers to withdraw irreversibly from the labour market, thereby leading to permanent labour supply effects. Third, other supply-side factors, such as living standards and/or demand for leisure, cannot plausibly account for the large differences in effective retirement ages observed in the OECD area, and even less so for the fact that these differences have widened over time. ${ }^{5}$ This hints at a significant impact of retirement incentives embedded in social systems. Finally, adjusting these systems to better cope with ageing populations is a main policy target in OECD countries and is the main instrument available for policymakers to raise labour force participation of older workers.

4. The remainder of this paper is organised as follows. Section 2 assesses early retirement incentives embedded in pension schemes and other welfare systems such as unemployment, disability or special early retirement benefits that have been used as pathways into early retirement across countries and their evolution over time. Section 3 presents cross-country econometric evidence about the overall impact of these schemes on the retirement decision. Section 4 provides more in-depth econometric analysis, based on panel data estimates. Section 5 concludes and discusses policy options to raise the labour force participation of older workers while at the same time improving social welfare.

\section{Early retirement incentives embedded in old-age pension systems and other social transfer programmes}

5. Three main characteristics of old-age pension systems affect the retirement decision of older male workers. First, higher pension benefits make retirement affordable (income effect). Second, implicit marginal taxes on continuing to work tend to deter workers from remaining in the labour market ("substitution" effect). Third, even though a person could in theory borrow to finance retirement before the age of entitlement to pension benefits, this does not occur frequently in practice, for a variety of reasons. As a result, standard and early ages of eligibility to benefits also affect the retirement decision. In the following, these different parameters of pension systems are described.

\section{Standard and early ages of entitlement to old-age pension benefits}

6. In theory, the age of eligibility to a pension should not necessarily affect the actual age of retirement. The reason is that rational forward-looking individuals could always set their retirement age at

\footnotetext{
4. For some recent considerations on these factors, see for instance OECD (2003a). In addition, an OECD thematic review on older workers is currently being conducted, with reports already published on Belgium, Sweden and Switzerland (OECD, 2003b,c,d).

5. For instance, despite being ranked among the highest OECD countries in terms of GDP per capita, Japan and the United States have significantly above-average participation rates for older workers. Similarly, demand for leisure is unlikely to differ drastically across OECD countries given their economic and sociocultural integration. However, these factors may have contributed to a common trend decline in participation rates of older workers within OECD countries over the past decades, at least to the extent that they have dominated the opposite effects of higher life expectancy and improved health status. For instance, Johnson (2000) provides evidence of negative participation effects of rising living standards for a panel of developed countries, while Costa (1997) suggests similar effects from rising demand for leisure - associated with declining relative prices and improving quality of leisure goods. Nevertheless, these explanations for declining effective retirement ages in the OECD area are not fully convincing. Indeed, they would imply a concomitant trend increase in leisure time during working life. Yet, over the last three decades declines in working time have been modest compared with those in effective retirement ages.
} 
the optimal level chosen to maximise their welfare, by trading off between consumption and leisure/retirement over their life cycle. They could borrow in capital markets if they wanted to retire before they can draw a pension, and conversely they could continue working and saving if they wanted to retire after the official age of retirement. With such behaviour the actual retirement age would be determined only by the level of pension wealth and its change or the implicit tax on continued work (see below).

7. However, there is evidence that actual retirement decisions do not conform to standard life-cycle models, at least on this specific point, as these cannot explain why many workers actually retire at early and standard ages (Gruber and Wise, 2002). At least four factors may account for this empirical regularity: i) some individuals are "liquidity constrained", which makes them unable to borrow in order to retire before pension benefits are available; ii) custom or accepted practice induces people to retire at "customary" ages (Lumsdaine et al., 1996); iii) workers are myopic or information constrained, i.e., they do not assess accurately actuarial incentives/disincentives to continued work embedded in pension systems and thus tend to retire at the earliest age at which benefits become available; and, in some cases, iv) individuals may not be allowed to continue working after the standard retirement age.

8. The standard age of eligibility to pension benefits differs substantially across OECD countries (Table 1). It is currently set at 65 years in most of them, but ranges for males from a low of 60 in a few countries (France, Korea, Slovak Republic and Turkey) to a high of 67 in Norway and Iceland (and is gradually being raised to that age in the United States). There is somewhat wider cross-country variance in standard ages for females because some countries still keep it lower than for males, even though gradual convergence towards male levels has already started in most of them, or is scheduled to do so in the future. There are even greater cross-country differences in early eligibility ages, but interpreting their impact on actual retirement is not straightforward because pension penalties for early withdrawal also differ considerably.

9. In the majority of OECD countries, standard and - to a lesser extent - early retirement ages have remained constant since the late 1960s. In those countries where changes have occurred, a general pattern emerges of reductions in the 1970s-1980s, followed by few increases since the beginning of the 1990s. In New Zealand, the rapid transition from 60 to 65 in the standard retirement age during the 1990s was accompanied by an increase in the labour force participation of the 55-64 age group by over 15 percentage points - a larger rise than in any other OECD country over the past three decades.

[Table 1. Standard and early ages of entitlement to old-age pension benefits]

\section{Replacement rates and pension wealth levels}

10. In theory, and under certain conditions, the level of public pensions should have no direct effect on labour participation. For example, if contributions to an earnings-related pension system were perceived as savings, pension benefits were equal to the amount of contributions paid (in present value terms), and the interest rate was equal to the rate of growth of total wages, ${ }^{6}$ then pension systems should have no effect on labour supply and lifetime consumption (Aaron, 1982, Chapter 2; Disney, 1996, Chapter 7). ${ }^{7}$ Indeed,

6. If, as is often the case in practice, the real interest rate is higher than the growth rate of real wages, pension wealth is lower under a PAYG system that under a funded system or in the absence of any pension scheme. Therefore, the existence of a PAYG system reduces consumption and pushes individuals to work longer.

7. Lifetime retirement models also rely on the assumption that individuals have a long planning horizon in making their labour supply decisions and fully recognise the value of accumulating entitlements to future benefits associated with contributions paid. 
such a scheme would simply reduce personal saving during working life by the amount of contributions paid, i.e. the savings rate would be low if contributions and replacement rates were high, and vice versa. ${ }^{8}$

11. In practice, however, redistributive elements in schemes, changes in scheme provisions, as well as demographic changes, lack of information and short time horizons, imply that public pension systems affect the distribution of income and wealth both across and within generations, thereby creating "wealth effects" on the retirement decision (Disney, 1996). Indeed, the future stream of benefits to which older workers are entitled can be regarded as a component of their total wealth, which is often called "pension wealth". Hence, the introduction of a PAYG system, or an unexpected ${ }^{9}$ rise in the level of pension benefits not exactly offset by an increase in their contributions, raises the net pension wealth of older workers. This stimulates their demand for both consumption and leisure, thereby pushing them to retire earlier. ${ }^{10}$ This negative effect on labour participation then fades over time as new cohorts of older workers, unaffected (or even negatively affected) by this inter-generational redistribution, replace older ones. ${ }^{11}$

12. The most straightforward indicator of the generosity of pension benefits is the replacement rate, which corresponds to the ratio of annual benefits to earnings just prior to retirement. ${ }^{12}$ However, there is no obvious method to compute this indicator because its level varies depending on a large number of factors. ${ }^{13}$ For the purpose of this paper, replacement rates have been constructed for illustrative cases under a set of common simplifying assumptions. ${ }^{14}$ They are defined here as average expected replacement rates over a future five-year period, and are computed at ages 55, 60 and 65 for 22 OECD countries. ${ }^{15}$ In order to make

8. Even if the amount of contributions is so high that it exceeds desired saving, such PAYG scheme would still not affect labour supply behaviour as long as individuals can borrow at the same rate used to compute pension benefits.

9. Expected increases in the generosity of pension benefits yield smaller labour supply effects than unexpected ones. The farther in advance changes in scheme provisions are announced, the more workers increase their consumption and reduce their savings in anticipation of future pension wealth gains (Feldstein, 1974), the smaller the increase in their total wealth and the corresponding impact on their retirement decision.

10. The more workers care about the welfare of their descendants and realise that the cost of higher benefits will have to be borne by them, the more changes in the generosity of benefits are offset by changes in bequests, and the smaller the "wealth effect" on labour supply.

11. Anderson et al. (1997) suggest that the large unanticipated increase in the level of social benefits that took place in the United States during the 1970s created windfall gains in the value of retirement assets of those nearing retirement, thus inducing some of them to anticipate their retirement decision. Unlike older workers, younger cohorts were less affected because they had time to adjust their savings patterns to reflect these windfalls.

12. Earnings just prior to retirement are assumed to be a reasonable proxy for expected earnings from work, which in theory should be used in the calculation.

13. For instance, in flat-rate pension systems, these factors may include household composition and the amount of other income and/or assets. In earnings-related pension schemes, they usually include inter alia the length of the working life and other periods to be credited for pension purposes (such as education, child care or unemployment), as well as the age-earnings profile over the worker's career. Furthermore, these schemes may differ across sectors and/or types of jobs.

14. Replacement rates are computed for, and averaged across, six different situations (three earnings levels and two marital situations), under the main assumption that the illustrative worker considered enters the labour market at age 20 and has an uninterrupted full-time career in the private sector until retirement. See Appendix 1 for details.

15. Unlike expected replacement rates, simple replacement rates at specific retirement ages could have been misleading. For instance, if in two countries the minimum eligibility age is 65 , a worker retiring at age 64 
ECO/WKP(2003)24

\section{Box 2. A brief overview of the datasets on retirement incentives available at the OECD}

The OECD has recently created models simulating retirement incentives. These have been used in slightly different ways in a number of recent OECD publications.

Casey et al. (2003) follow and update other recent OECD work (OECD, 2002). They present net replacement rates (i.e. taking into account the tax treatment of earnings and benefits) and net changes in pension wealth from working for an additional year for both old-age pension and early retirement schemes, taken as a share of earnings. ${ }^{1}$ In this framework replacement rates are calculated as:

$$
R_{R}=P_{R} / Y
$$

where $R_{R}$ is the replacement rate at age $R, P_{R}$ is the pension level if retiring at age $R$ and $Y$ is the earnings level just before retirement. Net changes in pension wealth are calculated as:

$$
\Delta\left(N P W Y_{R}\right)=\left[N P W Y_{R+1}\right] *\left[S_{R+1} /(1+r)\right]-N P W Y_{R},
$$

where $N P W Y_{R}$ is net pension wealth as a proportion of earnings at retirement age $R, S_{R+1}$ is the survival function at age $R+1$ (i.e. the probability of being alive at age $R+1$, conditional upon being alive at $R$ ) and $r$ is the real discount rate. Data is available for 15 OECD countries and provides an assessment of the incentives to retire in current systems (at their steady state) for single individuals aged from 55 to 70 at various levels of income.

In the absence of readily available historical data on the tax treatment of earnings and benefits for all countries, the present paper follows older OECD work (Blöndal and Scarpetta, 1998) and employs gross replacement rates (i.e. before tax) and gross changes in pension wealth for 22 countries. The latter are calculated as:

$$
\left.\Delta\left(P W Y_{R}\right)=\left[\left[P W Y_{R+5}\right] *\left[S_{R}+5\right) /(1+r)^{5}\right]-P W Y_{R}-(\text { CONTRIBUTIONS })\right] / 5,
$$

where $P W Y_{R+5}$ is gross pension wealth as a proportion of earnings at retirement age $R+5, S_{R+1}$ is the survival function at age $R+5, r$ is the real discount rate and CONTRIBUTIONS is the present value of all contributions to the pension system paid between $R$ and $R+5^{2}$. These results are presented for individuals under old-age pension and early retirement schemes at ages 55, 60 and 65 only. Replacement rates (but not implicit tax rates) are calculated not only for single workers but also for couples with a dependent spouse. These data have been extended back to 1967 for most countries.

These two datasets are consistent with each other. They use exactly the same parameters (accrual rates, actuarial adjustments for early/deferred retirement, mortality tables...). ${ }^{3}$ Gross replacement rates are similar for the 15 pension systems where the two presentations can be compared. Implicit tax rates differ, but simply because formulas used to compute them differ. In practice, the first presentation contains more precise results, because it takes into account the tax treatment of earnings and benefits. However, the second dataset covers a much wider range of countries and (most importantly) contains estimates of retirement incentives for the past and is therefore used below in panel-data econometric estimates of the retirement decision.

1. This is equivalent to the implicit tax on continued work with an opposite sign.

2. As for the computation of the present value of pension flows (i.e. pension wealth), the computation of the present value of contributions takes into account mortality risks: see Appendix 2 for details.

3. However, in the case of France, the effects of the 2003 pension reform are taken into account in the present paper, while they were not yet incorporated at the time Casey et al. published their study.

receives no benefit and his/her replacement rate is zero in both cases. Yet, after waiting for a year, he/she may receive a significantly higher pension in one country than in the other. Therefore, considering simple replacement rates at specific ages would incorrectly suggest that both schemes are equally unattractive. Comparatively, average expected replacement rates over a five-year period provide a more accurate picture. 
the calculations manageable for a wide range of countries and time periods, a number of simplifying assumptions are made (Appendix 1). In particular, unlike in other recent OECD work (see Box 2 for details), the taxation of earnings and benefits is omitted, i.e. only gross replacement rates are computed. In addition, the age-earnings profile over the working life is assumed to be flat, so that changes in the earnings base used in the pension benefit formula are, in general, not reflected in the calculations.

13. At present and including recent reforms, ${ }^{16}$ average expected gross replacement rates at ages 60 and 65 differ noticeably across OECD countries (Figure 2). At age 60, they range from 0 in those countries where the early age of eligibility is at least 65 (Austria, ${ }^{17}$ Iceland, Ireland, Norway, ${ }^{18}$ New Zealand, United Kingdom) to over 70 per cent in several countries where people can claim generous old-age pension benefits in their early sixties (Korea, Luxembourg, Netherlands, ${ }^{19}$ Portugal, Spain). At age 65, they range from less than 40 per cent in Ireland and Norway to as high as 100 per cent in Hungary and Luxembourg.

\section{[Figure 2. Average expected replacement rates over next five years in current old-age pension systems]}

14. Expected replacement rates rose in the vast majority of OECD countries between the end of the 1960 s and the end of the 1980s (Figure 3). The rise at age 60 was mostly due to declines in early retirement ages (increased eligibility), while at age 65 it was mainly caused by increased pension levels. By contrast, since the beginning of the 1990s expected replacement rates have been stabilised (at age 65) and even reduced (at age 60). ${ }^{20}$ However, these broad trends mask considerable differences across countries. While expected replacement rates remained fairly stable in some countries over the past three decades, they rose

16. These figures refer to the "steady state" of current pension systems. As a consequence, they incorporate all future effects of recently enacted reforms (e.g. Austria, France, Italy, Sweden). In addition, in those countries where old-age pension systems are not yet mature (e.g. Korea, Norway to a lesser extent), or where new components of the system will mature only gradually (e.g. the Superannuation Guarantee scheme in Australia, to which participation became mandatory only in 1992), the figures reported in Figure 2 are the replacement rates provided by these systems once they reach maturity. Not incorporated in the calculations are the projected rise in the standard retirement age from 60 to 65 in Korea (as part of the 1998 reform), the future increase in the minimum retirement age (i.e. at which superannuation savings can be drawn) from 55 to 60 over the period 2015-2025 in Australia, as well as the projected rise in the minimum retirement age from 60 to 65 in Japan (as part of the 2000 reform which came into law in April 2002). See Appendix 3 for details.

17. This does not incorporate early retirement due to long insurance years, which can be accessed from age 61.5 with a 69.5 per cent replacement rate for the theoretical worker considered.

18. This does not incorporate the early retirement (AFP) scheme, which can be accessed from age 62 with a 34.5 per cent replacement rate for the theoretical worker considered.

In the case of Netherlands, the modelling at age 60 refers to a "typical" early retirement (VUT) scheme. However since the early 1990s these PAYG schemes have been progressively transformed into less generous, fully-funded, systems. More recently, a government plan was presented to Parliament, which proposed to abolish the preferential fiscal treatment of early retirement schemes. As a result of these transformations, the current expected replacement rate at age 60 may be overstated.

Australia and Korea are two exceptions (Figure 3). However, in both countries, higher replacement rates in current pension systems (at their steady state) compared with the late 1980s reflect their maturation (the Superannuation Guarantee Scheme in Australia, the National Pension Scheme in Korea: see Appendix 3), rather than an increased generosity in benefit payments. 
very significantly in others (Netherlands, Spain, Finland, Sweden at age $60 ;{ }^{21}$ Finland, Spain, Sweden, and to a lesser extent Ireland and Norway at age 65), in particular at early ages.

[Figure 3. Historical changes in average expected replacement rates in old-age pension systems]

\section{Implicit marginal taxes on continued work in old-age pension systems}

15. Pension wealth, defined as the present value of the future stream of pension payments to which a person is entitled over his or her remaining life-time, is a broader indicator of pension generosity than the replacement rate. Most importantly, at each age, changes in net pension wealth from working for an additional year (additional benefits minus additional contributions) can be regarded as an implicit marginal tax (if negative) or subsidy (if positive) on continued work.

16. More precisely, provided that the individual is already eligible for a pension, and that the receipt of a pension cannot be combined with earnings from work, remaining in the labour market for an additional year implies foregoing one year of benefits. If the cost in terms of foregone pensions and contributions paid is exactly offset by an increase in future pension benefits, the pension system is said to be "actuarially neutral", ${ }^{22}$ but if this cost is not offset, there is an implicit tax on continued work.

17. Labour supply effects of implicit taxes on continued work created by pension schemes are theoretically ambiguous (Mitchell and Fields, 1984), as - similar to changes in wages - they produce opposite income and substitution effects. ${ }^{23}$ In practice, however, there is overwhelming empirical evidence that substitution effects are dominant (Lazear, 1986; Lumsdaine and Mitchell, 1999), so that implicit taxes on continued work tend to bias the retirement decision towards early labour market withdrawal.

18. In the following, new results (see Box 2) for implicit taxes on continuing working for five more years are presented (for a single worker with average earnings at ages 55, 60 and 65) for both normal oldage pension systems and early retirement schemes. They are based on the same assumptions used in the calculation of replacement rates, as well as on a number of additional ones (Appendix 2). In particular, when making his decision to withdraw from the labour market or to continue to work, the individual is assumed to expect constant economy-wide real earnings if choosing to work. While this has no impact on implicit tax rates in flat-rate schemes, it tends to over-estimate them in earnings-related ones, all the more so as the reference period for earnings used in the benefit formula is long (e.g. the "new" pension system in Italy). According to Figure 4, implicit taxes created by old-age pension systems are fairly small - and even

21. Three countries for which Figure 3 also shows an increase in replacement rates at age 60 are Australia, Korea and Portugal. However this increase did not affect participation patterns over the past decades, either because it is too recent (Portugal, following the 2002 pension reform which lowered the minimum retirement age from age 65 to 55) or has not yet occurred (Australia and Korea, where pension schemes are not yet mature: see above).

22. This definition refers to actuarial neutrality at the margin (i.e. for an additional year of work). Actuarial neutrality on average (i.e. over the life cycle of the individual) is achieved when the (present) value of pension benefits received during retirement is equal to the (present) value of contributions paid during the working life.

23. As suggested by Lazear (1986), over and above the usual wage rate, the implicit tax/subsidy on continued work can be regarded as a component of the "true wage". From this perspective, a rise in the implicit tax on continued work - due for instance to a cut in the pension accrual rate - is equivalent to a fall in the wage rate, producing opposite substitution and income effects: the lower financial gain from postponing retirement reduces the opportunity cost of retiring earlier (negative substitution effect) but, at the same time, provides lower income for each future year of work, thereby inducing later retirement (positive income effect). 
negative in a few cases (France and Luxembourg) - at early ages, but they have a clear tendency to rise as individuals age. The average implicit tax rate across 22 OECD countries is found to be below five per cent (ten per cent excluding France and Luxembourg) at age 55, while it is above 30 per cent at ages 60 and $65 .^{24}$

\section{[Figure 4. Average implicit tax rates on continued work in current old-age pension systems]}

19. The dispersion of implicit taxes on continued work across OECD countries is very large, especially at high ages. ${ }^{25}$ In addition, these differences usually match fairly well - though not perfectly those in expected replacement rates (Figure 5 and Appendix 4): countries with high replacement rates often also have large implicit taxes on continued work (e.g., France, Luxembourg and Netherlands at age 60, Austria, Italy and Spain at age 65), and vice versa (Iceland, Ireland, New Zealand, United Kingdom). Broadly speaking, implicit taxes are high in Continental European countries (with a few exceptions) compared with Nordic and English-speaking ones as well as Japan.

\section{[Figure 5. Average expected replacement rates and implicit tax rates on continued work in current old-age systems]}

20. Like expected replacement rates, albeit to a lesser extent, implicit taxes on continued work rose through the 1970s and the 1980s, but have started to stabilise and even decline in some cases since the early 1990s (Figure 6). Increases were large in some Continental European countries (France before the 2003 reform, Netherlands) compared with English-speaking and Nordic countries, primarily for people in their early $60 \mathrm{~s}$. These observations are consistent with historical labour force participation patterns, i.e. with trend declines in older workers' participation being stronger in Continental European countries and having flattened out since the early 1990s.

\section{[Figure 6. Historical changes in average implicit tax rates on continued work in old-age pension systems]}

\section{Implicit marginal taxes on continued work in other social transfer programmes}

21. In many OECD countries, relatively easy access to various social transfer programmes has enabled certain categories of older workers to withdraw from the labour market before the early age of entitlement to old-age pension benefits. Such schemes, which include special early retirement provisions as well as unemployment-related and disability benefits (Blöndal and Scarpetta, 1998; Casey et al., 2003), often entail high implicit taxes on continued work, for two main reasons: replacement rates are usually high; and pension rights continue to accrue even if, in some cases, at a reduced rate.

22. No attempt is made here to be comprehensive in the coverage of these programmes. Rather, in order to provide a rough assessment of early retirement incentives arising from them, a "typical early retirement route" is modelled under the following simplifying assumptions:

\footnotetext{
24. Implicit tax rates at age 65 are actually higher than at age 60 in the majority of OECD countries. Nevertheless they are very low in those countries where it is possible to combine work with the receipt of a full or reduced pension (see Appendix 2), which lowers the OECD average (e.g. Canada, Germany, Luxembourg, Netherlands, New Zealand).

25. Excluding France and Luxembourg -where high implicit subsidies on continued work tend to inflate variance across countries at age 55-, the cross-country dispersion of implicit tax rates is almost four times as high at age 60 as at age 55, and is about 50 per cent higher at age 65 than at age 60 .
} 
- In those countries where unemployment-related benefits can be used de facto to bridge the time until people are entitled to an old-age pension, ${ }^{26}$ implicit taxes on continued work are computed for the same illustrative cases as for old-age pension schemes.

- Where unemployment-related schemes cannot be used effectively as an early retirement device but other schemes are available, ${ }^{27}$ the latter are considered.

- Where no social transfer programme can be used to withdraw from the labour market before the minimum pensionable age, ${ }^{28}$ the "early retirement route" is simply the old-age pension pathway into retirement.

23. It should be stressed, for at least two reasons, that the implicit tax on continued work obtained using the above methodology provides only a rough estimate of the magnitude of retirement incentives embedded in early retirement schemes. First, the focus on a single "early retirement route" leaves aside the participation effects of a number of other social transfer programmes that may actually be used as early retirement devices. Second, the actual strictness of eligibility criteria for these programmes is imperfectly reflected in the calculations. For instance, even in those countries for which it has been assumed that retirement on account of disability is not - or no longer, as in Sweden an available option, due to the official strictness of eligibility criteria, the share of disability benefit status in non employment actually grew significantly during the second half of the 1990s (e.g. Australia, Sweden, United States: see OECD, 2003e).

24. Keeping these caveats in mind, the results are broadly in line with those obtained for old-age pension schemes. First, the dispersion of implicit tax rates in the "early retirement route" is very large across OECD countries (Figures 7 and 8, Panels B). Second, implicit tax rates rose throughout most of the 1970s and the 1980s, especially at age 55, as early retirement schemes were created and/or were becoming more generous. However, this expansion has come to a halt since the early 1990s, and has even been reversed in some countries (e.g., Sweden, or Finland more recently).

\section{Effects of implicit tax rates on labour market participation of older workers: preliminary cross-country evidence}

\section{Effects of implicit tax rates on continued work}

25. The implicit tax on continued work is a key summary indicator of retirement incentives embedded in pension systems and early retirement schemes, because it captures some of the effects of both eligibility ages and the generosity of benefits. Ceteris paribus, the higher the replacement rate, the higher is the "opportunity cost" of, and the implicit tax on, continued work (Figure 5 and Appendix 4). Similarly, the higher the minimum pensionable age, the lower is the implicit tax on continued work before this age, ceteris paribus. ${ }^{29}$ Thus, there is a rationale for focusing primarily on implicit taxes on continued work when assessing participation effects of retirement incentives embedded in pension schemes.

26 Belgium, Finland, France, Germany, Netherlands, Portugal, Spain, United Kingdom.

$27 \quad$ Austria and Luxembourg (where disability benefits were considered given their widespread incidence among pensioners), as well as Ireland and Norway (where the modelling refers to the pre-retirement allowance and the special early retirement programme, respectively).

Australia, Canada, Iceland, Italy, Japan, Korea, New Zealand, Switzerland, United States.

To see this, one can consider a purely illustrative country in which the pensionable age would be 100 . Whatever the generosity of future benefits and the pension accrual rate between 60 and 65, pension wealth would be very low at both ages because pension flows to be received far into the future would be heavily 
26. As an illustration of potential participation effects of retirement incentives embedded in "regular" pension schemes, Panels A in Figures 7 and 8 plot, for two age spans (55-59 and 60-64), the fall in male labour force participation an implicit measure of labour market withdrawal against the corresponding implicit tax on continuing working for five more years. ${ }^{30}$ The fall in labour force participation over the age span 55-59 appears to be unrelated to the implicit tax on continued work between ages 55 and 60 (Figure 7, Panel A). This finding should come as no surprise, insofar as implicit taxes in regular pension schemes are usually low and fairly similar across countries at age 55 (with the exception of France and Luxembourg), while differences in participation rates are large. By contrast, there is a significant bivariate correlation between the fall in labour force participation over the age span 60-64 and the implicit tax on continued work between 60 and 65 (Figure 8, Panel A). Both labour market withdrawal and implicit taxes are generally higher in Continental European countries than in Japan, Korea, English-speaking and Nordic countries.

27. While no clear link emerges between the fall in male labour force participation over the age span 55-59 and the implicit tax in "regular" pension systems (Figure 7, Panel A), a strong relationship emerges when the early retirement route is considered (Figure 7, Panel B). For the 60-64 age group, taking into account early retirement schemes brings a more limited improvement to the cross-country relationship between labour force participation and implicit tax rates (Figure 8, Panel B). These results hint at larger participation effects of early retirement programmes on workers in the 55-59 age group than on those in the 60-64 age group, whose retirement decision seems to be comparatively more influenced by regular pension schemes. Taken at face value, the estimated slope coefficients suggest that a ten percentage points decline in the implicit tax rate reduces the fall in participation rates between two consecutive (five-year) age groups of older workers by three to four percentage points, depending on the age group considered.

\section{Effects of "aggregate" labour tax rates}

28. A broader, aggregate, labour tax rate may also be computed as the sum of two components: $i$ ) the implicit tax on continued work (on a gross basis, i.e. less the rate of contribution to the old-age pension system so as to eliminate double counting) expressed as a percentage of total labour costs (rather than as a percentage of gross wage earnings); and, ii) the standard labour tax rate (including pension contributions), also expressed as a percentage of total labour costs. ${ }^{31}$ As shown in Figures 7 and 8 (Panels C), the crosscountry correlation is increased (in absolute value) for the 60-64 age group when the implicit tax on continued work is replaced by this aggregate labour tax rate. ${ }^{32}$ This finding suggests that even though they are not covered in this paper, labour taxes may also have a negative impact on labour force participation of male older workers, consistent with a dominant substitution effect.

discounted. Therefore, the change in pension wealth from continuing working between 60 and 65 would also be very small.

Strictly speaking, people in the 50-54 and 55-59 age groups in 1999 belong to different birth cohorts. As a consequence, as computed in Figure 7, the difference in participation between these two age groups reflects not only a participation effect but also a cohort effect. However, in practice, the latter is very small compared with the former. Therefore, using the difference in participation within a given cohort (i.e. the participation rate of the 55-59 age group in 1999 less the participation rate of the 50-54 age group in 1994) would leave Figure 7 unaffected. The same applies to Figure 8 (55-59 and 60-64 age groups).

31. The standard labour tax rate for single workers with average production worker (APW) earnings is computed using the OECD tax models. Insofar as it is an average tax rate, the aggregate labour tax rate should also be viewed as an average rather than as a marginal tax. Moreover, the tax treatment of pension benefits is omitted from the calculations. Their incorporation would lower the aggregate labour tax rate, ceteris paribus.

32. However, the difference between slope coefficients in Panels B and C is not significant at the $5 \%$ level. 
ECO/WKP(2003)24

[Figure 7. Fall in male labour force participation between 50-54 and 55-59 and implicit tax rates on continued work]

\author{
[Figure 8. Fall in male labour force participation between 55-59 and 60-64 and implicit tax rates \\ on continued work]
}

\title{
4. Panel data econometric analysis of determinants of the labour force participation of older workers
}

\section{Previous studies}

29. A broad range of microeconometric studies of the retirement decision have been conducted over the past decade for a number of OECD countries (for a summary of individual country results, see for instance, Blöndal and Scarpetta, 1998; Gruber and Wise, 1999, 2002). They confirm that among a variety of factors - such as individual and household characteristics, wage earnings, retirement incentives embedded in old-age pension and early retirement schemes affect the labour supply of older workers. This result is also supported at the macroeconomic level by a variety of country case studies (see for instance the country-specific papers in Gruber and Wise, 1999). The latter are based on the idea that historical changes in old-age pension benefits rules offer "natural experiments" to study the participation effects of early retirement incentives. ${ }^{33}$

30. Comparatively, panel data macroeconometric evidence remains fairly limited. Blöndal and Scarpetta (1998) find effects of old-age pension and early retirement schemes on the labour force participation of older men aged 55-64 in a panel of 15 countries from 1971 to 1995. Johnson (2000) investigates old-age pension systems only and reaches similar conclusions for males in the 60-64 and 65+ age groups in a panel containing data for 13 countries at approximately ten-year intervals from 1880 to 1990. However, in both studies participation effects of early retirement incentives are found to be relatively moderate: for instance, for the 60-64 age group, Johnson estimates that only around 11 per cent of the decline in average participation rates from 1920 to 1990 can be explained by old-age pension variables.

31. The econometric analysis presented below combines the respective strengths of both studies, and as a result should a priori improve the estimates and allow richer analysis of the participation effects of retirement schemes. As in Johnson (2000), the calculation of implicit tax rates takes proper account of the possibilities to combine work with the receipt of a reduced or full pension. For instance, when benefits are not income-tested and no contributions to the pension system have to be paid, the implicit tax is simply zero because the stream of future payments is the same whether individuals keep working or not (Appendix 2). In this vein, less strict income testing has been traditionally at the root of low implicit taxes on continued work in the Swedish and Japanese pension systems, two countries with significantly aboveaverage participation rates of older workers. Also as in Johnson (2000), separate analysis is undertaken for the 55-59, 60-64 and 65+ age groups, while only the aggregate 55-64 age group was studied in Blöndal and Scarpetta (1998). There are several reasons for breaking up older males into three different age groups: i) the narrower the age band considered, the smaller the "demographic bias" involved in older males' participation trends; ${ }^{34}$ ii) isolating the 55-59 age group allows more precise analysis of the participation

33. For instance, when early and standard retirement ages are lowered and/or when early retirement benefits are allowed or extended, the social wealth of older workers and the implicit tax on continued work tend to rise. Therefore, historical experiences showing the effective age of retirement plummeting following benefit extensions (such as Germany and France respectively in the aftermath of the 1972 and 1981 reforms) or, conversely, soaring following benefit restrictions (New Zealand during the 1990s), can be interpreted as evidence of a powerful effect of retirement incentives on the labour supply of older workers.

To see how considering large age-bands tends to bias the analysis of participation trends, one can consider a hypothetical country where (different) participation rates of both the 55-59 and 60-64 age groups would 
effects of early retirement schemes, because the latter affect a priori to a lesser extent the 60-64 age group; and, iii) the implicit horizon for the retirement decision is shorter and, thus, probably more realistic in practice (individuals are implicitly assumed to decide whether they retire immediately or remain in the labour market for five additional years, rather than ten in Blöndal and Scarpetta (1998)). Finally, as in Blöndal and Scarpetta (1998), early retirement schemes are covered, which should significantly improve the analysis of the labour force participation of the 55-59 and - to a lesser extent - 60-64 age groups compared with Johnson (2000).

\section{The estimated equation}

32. For each of the 55-59, 60-64 and 65+ age groups separately, the equation adopted is estimated for a panel dataset of 22 OECD countries over the period $1967-1999 .{ }^{35}$ The specification is as follows:

$$
\Delta(P R M)_{i t} / P R M_{i t} * 100=\beta_{1} \times \mathrm{TAX}_{i t}+\beta_{2} \times(\operatorname{STANDARD~AGE})_{i t}+\beta_{3} \times \mathrm{UR}_{i t}+a_{i}+\gamma_{t}+\varepsilon_{i t},
$$

where $\mathrm{i}$ and $\mathrm{t}$ are country and time suffices, $\Delta(P R M)_{i t} / P R M_{i t} * 100$ is the difference in male labour force participation rates between two consecutive age groups (in per cent), TAX is the implicit tax on continued work, STANDARD AGE is the standard retirement age (included only in the regressions estimated for the 60-64 and 65+ age groups) and $U R$ is the unemployment rate of prime-age workers.

33. In each of the three equations, the dependent variable is the same as in Figures 7 and 8, i.e. the difference in labour force participation rates of older men between two consecutive age groups. Therefore these equations implicitly model withdrawal from the labour market, and thus the retirement decision, rather than the level of participation per se. The latter may be influenced by a number of other factors, including irreversible withdrawal from the labour market at earlier ages. ${ }^{36}$

34. The main explanatory variable characterising early retirement incentives is the implicit tax on continued work in the "early retirement route", as defined in Section 2 above. Another candidate would be the replacement rate (or, alternatively, the level of pension wealth), so as to capture income/wealth effects on the retirement decision. But, in practice, its strong correlation with the implicit tax rate makes it impossible to include both variables within the same regression. ${ }^{37}$ Keeping this caveat in mind, it should be said that the implicit tax on continued work per se sums up various dimensions of retirement incentives, such as the pension accrual rate but also the availability and generosity of benefits. Therefore, part of the wealth effects which could have entered the estimated equation in a straightforward way, via a replacement

have remained constant over past decades. A priori, one would expect the participation rate of the aggregate 55-64 age group to have also been stable. Yet it would actually show a decline, because population ageing increases the weight of older age groups with lower participation rates. In this hypothetical example, considering the 55-59 and 60-64 age groups separately would remove part of this demographic bias.

35. In eight of these countries, time series for participation rates and explanatory variables are actually shorter (see Appendix 1), implying that panel datasets used in the estimates are unbalanced.

For instance, despite no implicit tax on continued work beyond age 65, the participation rate of the 65-69 age group in Luxembourg ranks among the lowest in the OECD area, partially because high implicit taxes at earlier ages induce massive retirement before age 65. Despite these concerns about a specification in levels, such an equation has been tested with results that in qualitative terms resemble those of the preferred specification in first differences.

37. Including both the replacement rate and the implicit tax on continued work in the regressions would raise a multicollinearity issue -the cross-country correlation coefficient between both variables in 1999 is, for instance, above 0.8 for the 60-64 age group- and bias the estimated coefficients. 
rate or a pension wealth variable are, at least partly, indirectly captured by the implicit tax rate variable. In addition, in order to test for the existence of "customary" and/or "liquidity" effects, the standard retirement age is introduced as a separate explanatory variable in the regressions for the 60-64 and 65+ age groups. ${ }^{38}$

35. It should be stressed that incorporating implicit taxes on continued work in the estimated equation is implicitly consistent with the option value model of the retirement decision (see Appendix 5 for a brief overview). Indeed, most of the cross-country and time-series variance in option values of postponing retirement comes a priori from corresponding variance in implicit taxes on continued work, to the extent that changes in wage rates and preferences are likely to be comparatively smaller and less frequent. However, no attempt is made below at estimating a full option value model, mainly because of data limitations, particularly in a cross-country dimension. ${ }^{39}$

36. Discouragement effects among older workers associated with low employment opportunities are captured by the unemployment rate. Since the latter is jointly determined with participation, a potential endogeneity issue arises which is dealt with by using the unemployment rate of prime-age workers instead of the old-age unemployment rate. Insofar as the unemployment rate is negatively correlated with activity, this variable may also capture business cycle effects, in addition to discouragement effects.

37. Other influences on the retirement decision are controlled for using country and time fixed effects. In particular, as in Johnson (2000), secular retirement trends, such as increasing demand for leisure over time and/or wealth effects stemming from rising living standards, are captured by time dummies. These time fixed effects may also absorb all shocks common to all countries, such as irreversible withdrawal from the labour market by laid-off workers in the aftermath of the two oil shocks of the 1970s. ${ }^{40}$

38. However, other potential determinants of older workers' participation may vary both across countries and over time. These are not explicitly covered by the analysis but, to a limited extent, part of their influence might still be captured indirectly by other variables in the regressions. For instance, the rigidity of age-earnings profiles is supported by specific institutional arrangements (such as high minimum wage or stringent employment protection legislation) that may also affect the unemployment rate of primeage workers, a variable included in the regressions. Similarly, the low incidence of training for older workers may partially result from the fact that high implicit taxes lower the expected retirement age. But in any event, some omitted variable bias cannot be completely ruled out. ${ }^{41}$ In addition, implicit taxes are measured imprecisely, in part because of the number of simplifying assumptions underlying the

38. Not surprisingly, the standard - as well as the early- retirement age proved to be insignificant for the 55-59 age group.

Earnings over the past and potential future years of work, as well as the marginal utility of leisure, would be required to estimate the full model.

To a certain extent, such shocks reflect business cycles and are, therefore, already captured by the unemployment rate. However, time fixed effects were found to be significantly different from zero at the five per cent level in all regressions below.

For instance, no account is made for the fact that retiring often results from a joint decision made in a household context (see for instance Coile, 2003). Another omitted variable affecting the retirement decision is the presence of voluntary private pension schemes, especially in those countries where such plans are prominent, e.g. Australia, Canada or the United States. There is indeed ample empirical evidence that large disincentives to work are embedded in some of these schemes (Kotlikoff and Wise, 1987; Stock and Wise, 1990). However, they may affect more the age of departure from a particular firm than labour force withdrawal per se, especially when prior knowledge of their characteristics enables workers to smooth consumption and labour supply over the life cycle. 
calculations (Appendix 2), and also because the illustrative worker considered in the modelling may not be fully representative of the typical worker. ${ }^{42,43}$

\section{Econometric results}

39. For each of the 55-59, 60-64 and 65+ age groups, Table 2 presents three alternative regressions. Model A incorporates country-specific time trends rather than common time fixed effects in order to better capture country-specific retirement trends. ${ }^{44}$ As expected, implicit taxes on continued work, and the unemployment rate of prime age males are negatively signed and statistically significant. The standard retirement age appears to affect positively the labour force participation of workers aged 65 and over but, more surprisingly, it is not significant for the 60-64 age group. However, there is evidence that country-specific time trends unduly capture part of the participation effects of implicit taxes on continued work. Indeed, a simple regression of the estimated coefficients of country-specific time trends on a variable $^{45}$ representative of the magnitude of implicit taxes yields significant results at the five per cent level for each of the three age groups: the larger the incentive to retire early in a country, the larger the estimated coefficient of its (negative) specific time trend. This finding is likely to reflect the fact that changes in participation rates induced by abrupt changes in implicit taxes are usually gradual, and may thus be better captured by simple time trends.

40. Since Model A probably understates the coefficients of implicit taxes on continued work, in Model B country-specific time trends are replaced by common time fixed effects. All variables remain correctly signed and significant (including the standard retirement age for the 60-64 age group), but the coefficients of implicit taxes are larger, and do not differ significantly across age groups. ${ }^{46}$ Finally, Model C is the same as Model B, except that it is based on a more restrictive assumption regarding the

42. For instance, theoretical replacement rates computed for Spain are significantly higher than actual average replacement rates. One reason for this gap is the assumption of an uninterrupted career used in the modelling, which does not hold in practice in Spain due to persistently high unemployment until very recently. In addition, the calculation of implicit tax rates implicitly assumes that all workers are covered by the old-age pension system. As a result, it does not capture the trend increase in pension coverage experienced in a number of OECD countries over the past three decades.

43. There could also be a problem of reverse causality on two grounds: $i$ ) (older) voters with a strong preference for retirement may push towards lower eligibility ages and higher implicit tax rates; ii) the deterioration of employment opportunities of older workers may force them out of the labour market, thereby inducing governments to improve the generosity of pension systems and other social transfer programmes. However, Johnson (2000) suggests that the latter bias may be small in practice. Looking at major past changes in scheme provisions in a number of OECD countries, he finds that they have preceded, not followed, declines in older workers' participation.

In order to obtain meaningful coefficients for country-specific time trends, Model A is estimated on a balanced (14 countries over the period 1967-1999) rather than an unbalanced (14 countries and eight other for which time series for participation rates and explanatory variables are much shorter) panel dataset.

This variable takes the values 0,1 and 2 for those countries where retirement incentives embedded in oldage pension and early retirement schemes are classified respectively as low (Australia, Canada, Ireland, Norway, Sweden, United States), moderate (Germany, Portugal, Spain, United Kingdom) and large (Finland, France, Italy, Netherlands) on the basis of their implicit tax rates.

The coefficients are not statistically different at the five per cent level. However, the point estimate is smaller for the 55-59 age group. This finding comes as no surprise, given the difficulty to capture the complex influence of early retirement schemes on the retirement decision through a single quantitative variable. In particular, no account is made for the number of existing retirement routes and for the degree of strictness with which eligibility criteria (e.g. for granting disability pensions) are applied in practice. 
source of heteroskedasticity: ${ }^{47}$ the econometric results remained broadly unchanged, except that the coefficients on implicit taxes are somewhat smaller. ${ }^{48}$

\section{[Table 2. Panel data estimates of the labour force participation of older workers]}

41. The preferred specification (Model B) suggests that, on average, a ten percentage points decline in the implicit tax rate reduces the fall in participation rates between two consecutive (five-year) age groups of older workers by about $1 \frac{1}{2} 2$ percentage points. This result is consistent with existing panel data estimates at the macroeconomic level. In particular, estimated participation elasticities are fairly similar to those estimated for the 60-64 age group in Johnson (2000) and are somewhat larger than in Blöndal and Scarpetta (1998). ${ }^{49}$ In addition, the explanatory power of the regressions compares favourably with these two previous studies. On the basis of the coefficients estimated in Model B, past changes in implicit tax rates and standard retirement ages are found to explain a third (31\%) of the trend decline in older males' labour force participation in OECD countries over the last three decades. ${ }^{50}$ This contribution reaches $40 \%$ when the whole model (including the effect of rising unemployment rates in a number of continental European countries) is considered. This suggests that other determinants, such as preferences for leisure or "demand-side" factors, may have also played an important role in driving down participation rates.

42. However, these participation elasticities with respect to implicit tax rates are two to three times lower than those found in the simple cross-country regressions presented above ${ }^{51}$ (Figures 7 and 8 , Panels B) or in the microeconomic literature. For instance, in Gruber and Wise (2002), simulations using option value models estimated on separate microeconomic panel datasets for France, Belgium and the Netherlands suggest that a three-year delay in eligibility ages to old-age and early retirement schemes would raise the labour force participation of the 55-64 age group by about 20 percentage points in each of

47. More specifically, Model C corrects for country-wise heteroskedasticity (using Feasible Generalised Least Squares) rather than for individual heteroskedasticity (using the Huber/White/sandwich estimator of variance) as in Model B.

In order to assess the potential impact of demographic trends on the labour force attachment of older workers, specifications including the share of prime-age workers (aged 25-54) in total working-age population (aged 15-64) as an explanatory variable were also estimated. A priori, usual cohort-crowding effects would suggest a positive effect: the larger the number of prime-age workers compared with older ones, the higher the relative wage rate of the latter and the higher their labour force participation rate -to the extent that the substitution effect dominates the income effect. However, this demographic variable was found to have a significantly negative effect for both the 55-59 and 60-64 age groups. The rationale behind this result remains unclear. One possibility is that the increase in the share of prime-age, better educated workers which occurred throughout the 1970s and the 1980s deteriorated the employment opportunities of less educated older workers, all the more so in the presence of rigid age-earnings profiles. In any event, the coefficients of all other variables (implicit taxes, the standard retirement age and the unemployment rate) were insensitive to the introduction of this demographic variable.

The elasticities derived in Blöndal and Scarpetta (1998) are not directly comparable to those presented in Table 2, because the dependent variable was the participation level of the 55-64 age group rather than the fall in participation between two consecutive age groups. However, in practice, the potential impact of cuts in implicit tax rates on the labour force participation of the 55-64 age group, as calculated using Model B, appear to be larger than those simulated in Blöndal and Scarpetta (1998). This result comes as no surprise given the more disaggregated analysis adopted in the present paper.

This figure is a simple arithmetic average of contributions found for the 14 OECD countries (using the coefficients in Model B) for which lengthy time series of participation rates are available.

At first glance, the latter should be inflated by an omitted variable bias, but this intuition does not appear to be confirmed by the data. In particular, the unemployment rate variable is barely significant at the five per cent level and does not reduce the implicit tax rate coefficient in a cross-country regression. 
these countries. While past experience suggests a more moderate outcome for instance, the five-year increase in eligibility ages in New Zealand throughout the 1990s led to a 15 percentage points increase in labour force participation, it nonetheless points to significantly larger effects than in the regressions above.

43. The low elasticities typically found in panel data estimates may result from the difficulty to disentangle short and long-run effects and/or from the fact that historical changes in implicit tax rates - on which panel data (within) estimates are based - are measured with more error than current implicit tax rates levels. Therefore, it cannot be ruled out, as suggested by Johnson (2000), that simple cross-country regressions actually better capture the long-run participation elasticities of implicit tax rates.

\section{Conclusion and policies to increase labour market participation of older workers}

44. The analysis presented in this paper has shown that there is currently wide dispersion across OECD countries in implicit tax rates on continued work embedded in old-age pension systems and other social transfer programmes: they are high in most Continental European Countries, compared with Japan, Korea, English-speaking and Nordic countries. Simple cross-country correlations suggest that such taxes induce older male workers to anticipate their retirement decision. This finding is confirmed by panel data econometric estimates, for each of the 55-59, 60-64 and 65+ age groups. For the 55-59 age group, there is clear evidence that these effects result from a number of social transfer programmes, which have been used de facto as early retirement schemes, rather than from old-age pension systems themselves. For the 60-64 and $65+$ age groups, eligibility ages also appear to have a specific impact on the retirement decision, probably reflecting liquidity and/or customary effects. Furthermore, the prevalence of unemployment is also found to be a significant albeit smaller compared with retirement incentives influence on older workers' participation, possibly reflecting "discouraged worker" effects. This suggests that policies to reduce structural unemployment, which go beyond the scope of this paper, may also contribute to raise their labour market attachment.

45. As in previous studies, the estimated participation effects of implicit tax rates are significantly lower than those found in microeconometric analyses of the retirement decision. In addition, past changes in implicit tax rates and standard retirement ages are found to explain only a third of the trend decline in older males' labour force participation in OECD countries over the last three decades. Nevertheless, even with these relatively low participation elasticities, the potential impact of policy reforms on labour force participation appears to be fairly large, given the magnitude of retirement incentives still embedded in a number of old-age pension schemes and other social transfer programmes. ${ }^{52}$ In addition, moving towards more actuarial neutrality of retirement schemes would reduce the current bias towards early labour market withdrawal, thereby improving welfare.

46. Closing early pathways into retirement is the most straightforward step towards reducing implicit tax rates, for two main reasons: $i$ ) it would leave older workers in their late fifties and early sixties facing only the - significantly lower retirement incentives embedded in old-age pension systems; and ii) reforming old-age pension systems could well have fairly small participation effects if the access to early retirement schemes for people without special needs is not removed, as more workers would otherwise retire through these schemes. Likewise, reforming only some pathways into early retirement is likely to be ineffective because workers may leave the labour market via other schemes. Even though it is sometimes argued that early retirement systems help cover the risk of exclusion from the labour market at high ages, and may thus be particularly valuable when such risk is high and/or when workers are highly risk averse (Blanchet et al., 1996), these schemes also create large disincentives to continued work, so that it remains unclear in practice whether all early pensioners can be considered as permanently excluded from

52. For quantitative policy simulations based on the econometric estimates presented in section 4 , see Burniaux et al. (2003). 
the job market. Developing the employment chances of the elderly remains the first-best solution to deal with the exclusion problem.

47. Nevertheless, suppressing early retirement schemes would not be sufficient to bring implicit tax rates down to zero, because old-age pension schemes also entail implicit taxes on continued work, especially in some (mostly Continental European) countries and at high ages. To achieve a reduction in implicit tax rates embedded in old-age pension schemes, the most straightforward way is to adjust appropriately the value of pension benefits in case of anticipated and deferred retirement. While such adjustments currently apply in a number of OECD countries, they are usually below actuarially neutral levels.

48. In particular, many PAYG schemes do not provide actuarial bonuses for deferred retirement beyond the standard age (e.g., the flat-rate systems in Australia, New Zealand or the United Kingdom, but also, most importantly, the more generous earnings-related schemes in France ${ }^{53}$ and Netherlands until recently, or Norway), thereby discouraging work at high ages. For instance, assuming for simplicity a constant mortality rate of three per cent at each age, a real interest rate of three per cent, and contribution rate to the old-age pension system of 17 per cent, a rough calculation suggests that this bonus would have to be approximately equal to seven per cent for the pension system to be neutral (see formula in Appendix 4). And since the assumption of a constant mortality rate does not hold in practice, the actuarial bonus for deferred retirement should rise steadily with age in order to compensate for increasing mortality risks.

49. Implicit taxes on continued work could also be reduced by expanding the possibilities for older people to combine work with the receipt of a pension, which remain limited in most OECD countries. The key advantage of such an option, compared with setting appropriate actuarial adjustments for anticipated and deferred retirement is that it provides an easier and, at the same time as effective way to reduce implicit tax rates on continued work at high ages. However, its impact on effective retirement ages might be smaller in practice, ${ }^{54}$ because it makes earlier retirement affordable for otherwise "liquidity constrained" individuals. This presumption is corroborated by available empirical evidence, which suggests that past experiences in removing retirement earnings tests have rarely been followed by large pickups in the labour supply of the targeted age groups (Gruber and Orszag, 2000). In addition, to the extent that late retirement is often associated with individual characteristics such as high skills, high wages and above-average health (Peracchi and Welch, 1994; Haider and Loughran, 2001), letting older workers combine work with the receipt of a pension may, in practice, raise a vertical equity issue.

50. Another policy option available to policymakers (not tackled in this paper) is to encourage progressive retirement. In terms of hours worked, the labour supply effects of gradual retirement may actually not be very large, because some incumbent workers choose to work part-time, while they would work full-time under more rigid work schedules. However welfare is a priori improved. Indeed, since the marginal utility of work probably declines only gradually, "staged" retirement seems to be a route by which individuals may benefit from staying longer in the labour market. General lack of flexibility in working-time arrangements can be detrimental to part-time work at high ages, but some specific characteristics of old-age pension systems may also play an important role. For instance, pension benefits formulae based on previous income prior to retirement and/or the lack of pension coverage for parttimers ${ }^{55}$ may deter older workers from taking up part-time work. Furthermore, explicit partial retirement

53. The 2003 pension reform created a $3 \%$ actuarial adjustment for deferred retirement.

54. By contrast, its impact on welfare might be larger because it helps to reduce a capital market imperfection.

55.

Some countries apply entitlement rules based on a minimum number of hours (Denmark, Ireland) or a minimum income (Austria, Spain, Ireland, Germany, the United Kingdom), under which contributions to state pension schemes are not allowed. In addition, private occupational schemes do not always admit parttime workers (e.g. in almost a third of cases in the United Kingdom according to Ginn and Arber, 1998). 
schemes by which individuals can draw reduced retirement benefits while continuing to work part-time before the standard entitlement age to a full pension, are still not widespread across OECD countries (Denmark, Finland or the Netherlands are among the exceptions). Such schemes should be properly structured so as to limit their cost, while at the same time providing sufficient incentives to work parttime.$^{56}$ In this respect, an actuarially neutral system of gradual retirement may be thought of as an appropriate benchmark.

51. It should be stressed that even though policy measures aimed at reducing implicit tax rates would stimulate labour force participation, they would not be sufficient to ensure the long-run financial viability of old-age pension systems in most OECD countries. Such a goal will also need to be achieved by reducing the pension benefits, raising early and standard retirement ages and/or increasing taxes. The analysis presented in this paper suggests that the first two options (reducing replacement rates and/or raising eligibility ages), while improving the long-run financial situation of pension systems, would also incidentally stimulate labour force participation via two main channels: $i$ ) they would produce negative wealth effects, thereby delaying labour market withdrawal ${ }^{57}$ and $\left.i i\right)$ they would reduce implicit tax rates on continued work, ceteris paribus. In the case of delayed eligibility, implicit taxes would be reduced before the new legal ages but would be left unchanged beyond. As a result, the labour supply effect would likely be concentrated on those older workers aged under post-reform early and/or standard eligibility ages. This view is reinforced by the econometric evidence of "customary" and/or "liquidity" effects of eligibility ages on retirement behaviour presented above.

56. For instance, the partial pension system which prevailed in Sweden between 1976 and 2001 proved to be excessively costly (Disney, 1996), not least because it went far beyond actuarial neutrality by subsidising heavily part-time work.

57. However, these negative wealth effects result from intergenerational redistribution of pension wealth. Therefore, as already mentioned above, they tend to fade over time and, in addition, raise intergenerational equity issues. 


\section{REFERENCES}

AARON H. (1982), "Economic Effects of Social Security", Studies of Government Finance, The Brookings Institution, Washington D.C.

ANDERSON P., A. Gustman and T. Steinmeier (1997), "Trends in Male Labor Force Participation and Retirement: Some Evidence on the Role of Pensions and Social Security in the 1970's and 1980's", NBER Working Paper No. 6208, October

BLANCHET D., C. BROUSSE and M. OKBA (1996), "Retraite, pré-retraite, neutralité actuarielle et couverture du risque de chômage en fin de carrière", Economie et Statistique No. 291-292, 1/2.

BLÖNDAL S. and S. SCARPETTA (1998), "The Retirement Decision in OECD Countries", OECD Economics Department Working Papers, No. 98.

BURNIAUX J-M., R. DUVAL and F. JAUMOTTE (2003), "Coping with Ageing: a Dynamic Approach to Quantify the Impact of Alternative Policy Options on Future Labour Supply", OECD Economics Department Working Papers, forthcoming.

CASEY B., H. OXLEY, E. WHITEHOUSE, P. ANTOLIN, R. DUVAL, and W. LEIBFRITZ (2003), "Policies for an Ageing Society: Recent Measures and Areas for Further Reform", $O E C D$ Economics Department Working Papers No.369.

COSTA D. (1997), "Less of a Luxury: The Rise of Recreation Since 1888", NBER Working Paper No. 6054, June.

COILE, C. (2003), “Retirement Incentives and Couples' Retirement Decisions”, NBER Working Paper No.9496, February.

DISNEY R. (1996), Can We Afford to Grow Older: A Perspective on the Economics of Aging, Cambridge, Massachussets, MIT Press.

FELDSTEIN M. (1974), "Social Security, Induced Retirement and Aggregate Capital Accumulation", Journal of Political Economy 82, No. 5.

GINN J. and S. ARBER (1998), "How Does Part-Time work Lead to Low Pension Income?", in O'REILlEY J. and C. FAGAN (eds), Part-Time Prospects: An International Comparison of PartTime Work in Europe, North America and the Pacific Rim, Routledge, London.

GRUBER D. and P. ORSZAG (2000), "Does the Social Security Earnings Test Affect Labor Supply and Benefits Receipt?", NBER Working Paper No. 7923, September.

GRUBER D. and D. WISE (2002), "Social Security Programs and Retirement Around the World: Micro Estimation", NBER Working Paper No. 9407, December. 
GRUBER D. and D. WISE (1999), Social Security Programs and retirement Around the World, University of Chicago Press, Chicago.

HAIDER S. and D. LOUGHRAN (2001), "Elderly Labor Supply: Work or Play?", Center for Retirement Research Working Paper No. 2001-04, Boston College.

HERBERTSSON, T., and M. Orszag (2003), "The Early Retirement Burden: Assessing the Costs of the Continued Prevalence of Early Retirement in OECD Countries", IZA Discussion Paper No.816, July.

HOLZMANN R., L. MacKELLAR and M. RUTKOWSKI (2003), “Accelerating the European Pension Reform Agenda: Need, Progress, and Conceptual Underpinnings", in HOLZMANN R., M. ORENSTEIN and M. RUTKOWSKI (eds), Pension Reform in Europe: Process and Progress, The World Bank, Washington D.C.

JOHNSON R. (2000), "The Effect of Old-Age Insurance on Male Retirement: Evidence from Historical Cross-Country Data", Federal Reserve Bank of Kansas City Working Paper, No. 00-09, December.

KOTLIKOFF L. and D. WISE (1987), "The Incentive effects of Private Pension Plans", in BODIEZ., D. SHOVEN and D. WISE (eds), Issues in Pension economics, University of Chicago Press, Chicago.

LAZEAR E. (1986), "Retirement from the Labor Force", in ASHENFELTER O. and R. LAYARD (eds), Handbook of Labor Economics, Vol. 1, North Holland, Amsterdam.

LEE C. (2003), "Labor Market Status of Older Males in The United States, 1880-1940”, NBER Working Paper No. 9550, March.

LINDBECK A. and M. PERSSON (2003), "The Gains from Pension Reform”, Journal of Economic Literature 41, No. 1.

LUMSDAINE R. and O. MITCHELL (1999), "New Developments in the Economic Analysis of Retirement", in ASHENFELTER O. and D. CARD (eds), Handbook of Labor Economics, Vol. 3, North Holland, Amsterdam.

LUMSDAINE R., J. STOCK and D. WISE (1996), “Why are Retirement Rates so High at Age 65?”, in WISE D., Advances in the Economics of Aging, The University of Chicago Press, Chicago.

MITCHELL O. and G. FIELDS (1984), "The Economics of Retirement Behaviour", Journal of Labour Economics, Vol. 2, No. 1.

OECD (2003a), OECD Employment Outlook

OECD (2003b), "Viellissement et politiques de l'emploi - Belgique”, Paris.

OECD (2003c), « Ageing and Employment Policies - Sweden”, Paris.

OECD (2003d), “Viellissement et politiques de l'emploi - Suisse”, Paris.

OECD (2003e), «Transforming Disability into Ability : Policies to promote work and income security for disabled people", Paris. 
ECO/WKP(2003)24

OECD (2002), "Increasing Employment: the Role of Later Retirement”, Chapter V, OECD Economic Outlook, No. 72, December, Paris.

PERACCHI F. and F. WELCH (1994), "Trends in Labor Force Transitions of Older Men and Women", Journal of Labour Economics, Vol. 12, No. 2.

STOCK J. and D. WISE (1990), "Pensions, the Option Value of Work, and Retirement", Econometrica, 58, No. 5. 


\section{APPENDIXES}

\section{Appendix 1: Computing replacement rates in old-age pension systems and early retirement schemes: methodology and assumptions}

52. The replacement rate is classically defined as:

$$
R_{R}=P_{R} / Y
$$

where $R_{R}$ is the replacement rate at age $R, P_{R}$ is the pension level if retiring at age $R$ and $Y$ is the earnings level just before retirement.

For all possible retirement ages between 55 and 70, theoretical replacement rates in both "regular" and early retirement schemes are computed for three earnings levels (60, 100 and 140 per cent of average production workers' (APW) earnings) and two household compositions (single worker and married couple with dependent spouse of same age). Thus, these calculations enable computation of average replacement rates across six different situations. In addition to replacement rates at retirement age $\mathrm{R}$, average replacement rates between ages $\mathrm{R}$ and $\mathrm{R}+4$ are also constructed.

53. In order to make these calculations manageable for a wide range of countries and time periods, ${ }^{58}$ the following assumptions are made:

- The worker is assumed to enter the labour market at age 20 and work full-time in the private sector without interruption until retirement.

- The age-earnings profile over the working life is assumed to be flat, i.e. earnings are assumed to grow in line with countrywide average earnings. Under this assumption, lifetime earnings at the age of retirement are simply equal to 60,100 or 140 per cent of APW earnings, depending upon the earnings level considered. A key implication is that changes in the earnings base used in the pension benefit formula are, in general, not reflected in the calculations reported in this paper.

- The reported replacement rates only cover public schemes and mandatory or quasi-mandatory (as in Finland, the Netherlands ${ }^{59}$ Sweden, Switzerland or the United Kingdom) private occupational schemes. Occupational schemes offered by employers on a voluntary basis (as in Canada, Germany, Japan or the United States) are not covered.

58. The periods covered are all years since: 1967 for 14 OECD countries (Australia, Canada, Finland, France, Germany, Ireland, Italy, Netherlands, Norway, Portugal, Spain, Sweden, The United Kingdom and the United States), 1977 for New Zealand, 1987 for Korea, 1989 for Switzerland, 1993 for Luxembourg and Japan, 1995 for Austria, Belgium, and Iceland.

As mentioned in the main text, in the case of Netherlands, a "typical" early retirement (VUT) scheme is considered between ages 60 and 65. However, since the early 1990s these PAYGO schemes have been progressively transformed into funded systems. More recently, a government plan was presented to Parliament, which proposed to abolish the preferential fiscal treatment of early retirement schemes. As a result of these transformations, the current expected replacement rate at age 60 may be overstated. 
- The tax treatment of earnings and pension benefits is omitted. The concept of gross earnings considered in the calculations excludes employers' but includes employees' contributions to social security. Insofar as most OECD countries tend to apply a favourable tax treatment of pension benefits compared with gross wage earnings, gross replacement rates reported in this paper are generally lower than net replacement rates.

54. The main source for past and present pension rules is Social Security Programs Throughout the World, published every two years by the US Department of Health and Human Services. In the case of European member countries, the modelling also relies heavily on MISSOC (Social Protection in the Member States of the European Union), published by the Commission of the European Communities. Supplementary information is obtained from national sources and contacts, and in some cases from the background material collected in a previous OECD study (Blöndal and Scarpetta, 1998).

\section{Appendix 2: Computing pension, social wealth and implicit taxes on continued work: methodology and assumptions}

55. The calculation of pension wealth levels is directly derived from the computation of replacement rates presented above. However, unlike the latter which considers six different situations (three earnings levels and two marital situations), it is applied only to a single individual with APW earnings. As a first step, for each possible retirement age $\mathrm{R}$ between 55 and 70, the future stream of expected pension payments is computed from age $\mathrm{R}$ to age 105 . Pension wealth is then computed as the present value of this stream using the following formula:

$$
P W Y_{R}=\sum_{A=R}^{A=105}\left(S_{A} * R_{A}\right) /(1+r)^{(A-R)}
$$

where $P W Y_{R}$ is the pension wealth (as a proportion of earnings) for a single individual with APW earnings retiring at age $R, R_{A}$ is the replacement rate (computed as $P_{A} / Y$ ) that this individual would receive at age $A$ if he or she stops working now, $r$ is the real discount rate, and $S_{A}$ is the value of the survival function at age A. The latter is the probability of being alive at age A conditional upon being alive at age $\mathrm{R}$, and is derived from country-specific mortality tables published each year by the United Nations and the World Health Organisation. The survival function allows discounting more heavily pension flows received late in life, since the probability of receiving them is lower. In practice, with the combined effects of the survival function and the real discount rate, the discounted real value at age 65 of pension flows to be received at ages 90 and 100 are respectively about only five per cent and 0.1 per cent of the undiscounted real value of these flows.

56. Pension wealth levels are computed for all possible retirement ages between 55 and 70 . When the retirement age is lower than the earliest age at which a pension is available, the pension flow received before that age is simply zero. Social wealth levels are computed in a similar manner, except that the stream of payments considered is what the individual would receive through early pathways into retirement (unemployment, disability, special early retirement schemes) rather through the "regular" old-age pension system.

For the three retirement ages 55, 60 and 65 , changes in pension or social wealth from working for five additional years (i.e., from $\mathrm{R}$ to $\mathrm{R}+5$ ) are then computed as:

$$
D P W Y_{R}=\left[P W Y_{R}+5\right] *\left[S_{R}+5 /(1+r)^{5}\right]-P W Y_{R}-\sum_{A=R}^{A=R+4}\left[\left(S_{A} * C_{A} / Y\right) /(1+r)^{A-R}\right]
$$

where $\mathrm{C}_{\mathrm{A}} / \mathrm{Y}$ is the sum of employees and employers rates of contributions to the old-age pension system. The choice of five-year rather than annual changes in pension or social wealth is dictated by the fact that historical series of labour force participation statistics for older workers are available only for five-year age 
groups. Indeed, a possible measure of retirement incentives for each of the 55-59, 60-64 and 65-69 age groups is the change in pension or social wealth from remaining in the labour market during each of these life spans, i.e., from working between ages 55 and 60,60 and 65 and 65 and 70 respectively. When this change is negative, continuing to work for five additional years carries an implicit tax whose average over the five-year span is:

Average implicit tax on continued work beyond age $\mathrm{R}=-D P W Y_{\mathrm{R}} / 5$

57. The calculation of levels and changes in pension wealth relies on the following assumptions:

- All of the assumptions that are made to compute replacement rates (see Appendix 1).

- When making his decision to withdraw from the labour market or to work for five additional years, the individual is assumed to expect constant economy-wide real earnings if choosing to work. As a result, his lifetime earnings are expected to remain unchanged. This assumption has no effect on replacement rates, but it can affect the magnitude of calculated implicit tax rates across components of the pension system and more generally across countries. While there is no impact in flat-rate schemes, implicit tax rates can be over-estimated in earnings-related schemes, all the more so as the reference period for earnings used in the benefit formula is long (e.g. in the "new" pension system in Italy). This is because the calculations do not incorporate at the margin the automatic revaluation of past earnings in line with economy-wide earnings as is the rule in most OECD countries, i.e. the potential revaluation of past earnings that could take place as a result of the increase in economy-wide earnings during the additional year of work.

- Individuals are assumed to bear the cost of employers' contributions to the old-age pension system. An alternative choice, which would have produced lower estimates of implicit taxes on continued work, would have been to consider only the share of contributions directly paid for by employees.

- Pensions are assumed to be indexed to prices. This assumption implies a slight underestimation of implicit taxes on continued work in those countries/years where/when pensions are partially or fully indexed to wages. In addition, historical modifications in pension adjustment methods are not reflected pension wealth estimates.

- The real discount rate is set at three per cent. A higher (lower) rate would produce higher (lower) implicit taxes on continued work but would not affect the results qualitatively, in particular with regard to cross-country comparisons

- Strictly speaking, the above formula for changes in pension wealth applies only when full-time work cannot be combined with the receipt of any full or reduced pension. Even though this assumption holds for a worker with APW earnings in most countries and at most ages, this is not always true. For instance work can be combined with the receipt of a reduced old-age pension in Japan (subject to an income test) between ages 60 and 64, or with the receipt of a full pension in New Zealand. In such instances, the computation of the change in pension wealth from working for five additional years incorporates the stream of pension payments that the individual would receive over this five-year period (i.e., PWYR+5) incorporates not only the stream of pension payments received from age $\mathrm{R}+5$ but also those received between ages $\mathrm{R}$ and $\mathrm{R}+4$. As a result, changes in pension wealth are more positive (or less negative) and implicit taxes on continued work are lower than in the case of a strict income test. In the extreme case where the receipt of a pension is not income-tested and no contributions to the old-age pension system have to be paid (e.g. in New Zealand from age 65), the implicit tax on continued work is simply zero because the 
stream of pension payments remains unchanged whether the individual keeps working or not (see for instance Johnson, 2000).

\section{Appendix 3: Ongoing and already decided pension reforms}

58. The computation of expected replacement rates and implicit taxes on continued work in "current" systems - i.e. in systems at their steady state - (as presented for instance in Figures 2 and 4) incorporates the following changes, compared with 1999 systems (used for instance in Figures 7 and 8, Panels A): ${ }^{60}$

Australia: While no occupational pension scheme is modelled for 1999, the existence of the Superannuation Guarantee Scheme - which became mandatory in 1992 and was, therefore, not yet mature in 1999 - is incorporated in the steady state results. At the margin, an additional year of work increases future pension benefits paid out by this scheme, but it also reduces those received through the public old-age pensions system, due to an income test. As a result, implicit tax rates on continued work are higher in current systems at their steady state than in 1999.

Austria: The steady state results incorporate the long run effects of the 2003 pension reform. The latter includes a decline in the accrual rate - and a corresponding increase in the number of contribution years required to reach the maximum replacement rate - as well as larger actuarial adjustments for early and deferred retirement. As a result, implicit tax rates on continued work are lower in the current system at its steady state than in 1999.

Finland: A wide package of reforms to both old-age pensions and early retirement provisions will be phased in during 2003 and 2004. As a result, implicit taxes on continued work will be reduced at virtually all ages. For details, see OECD Economic Surveys: Finland, 2003.

France: The 1993 reform ("réforme Balladur") continues to be phased in over 1999-2003, thereby slightly lowering implicit tax rates on continued work beyond age 60. In addition, the calculations incorporate the 2003 pension reform. The latter includes an increase in the length of the contribution period required to get a full pension, lower actuarial adjustments for insufficient contribution years, as well as the introduction of an actuarial adjustment for deferred retirement. As a result, post-reform implicit tax rates are higher at age 55 (more precisely, the implicit subsidy which prevailed previously is now significantly lower) but lower at ages 60 and 65 .

Germany: An actuarial adjustment for early retirement at age 63 has been introduced following the 2001 reform.

Iceland: Occupational pension schemes became mandatory in 1974. Therefore, the "typical" scheme modelled here pays out benefits in 1999 but is mature only at the steady state.

Italy: Older workers are in the "old" pension system in 1999 but will be in the "new" one - which applies to all individuals having first entered the labour market after 1995 - in the long run. Therefore, steady state figures assume that all workers are in the new system. The latter entails lower implicit tax rates on continued work at virtually all ages, except beyond age 65 when pension rights stop accruing and, apart from exceptions, work can not be freely combined with the receipt of a pension.

Recent policy reforms are considered only to the extent that they affect the standard retirement age and/or the calculation of replacement rates and implicit taxes on continued work. Therefore those elements of recent reforms which are not relevant to the modelling are omitted from this Appendix (for a more detailed survey of recent pension reforms in 15 OECD countries, see Casey et al., 2003). 
Japan: The 2000 pension reform, which was implemented in April 2002, includes a reduction in the actuarial adjustment for deferred retirement beyond age 65, a small decline in the employee's pension accrual rate and an increase in the maximum number of covered years from 45 to 50 (assuming labour market entry at age 20). The projected rise in the minimum retirement age from 60 to 65 (over 2013-2025 for men and 2018-2030 for women) is not incorporated in the calculations. The consequences of this omission should be analysed carefully, since the introduction of an early pension available from age 60 is also scheduled.

Korea: The old-age pension system - which was introduced in 1988 - does not pay out benefits yet in 1999 but is assumed to be mature in the steady state. The latter does not incorporate the rise in the standard retirement age from 60 to 65 scheduled between 2011 and 2033.

Luxembourg: The 2001 reform introduced a supplementary accrual rate (the "93 rule") which has slightly lowered implicit tax rates on continued work. At the same time, replacement rates have been increased.

New Zealand: The standard retirement age is 64 in 1999 but 65 from 2001 onwards.

Norway: Unlike in the steady state, the pension system -introduced in 1967- is not fully mature yet in 1999.

Portugal: The 2003 reform reduced replacement rates at age 65, introduced an actuarially reduced pension from age 55 and an actuarial bonus for deferred retirement beyond age 65 . Overall, following this reform, implicit tax rates remain broadly unchanged for workers in their sixties.

Spain: The two per cent actuarial adjustment for late claiming, which did not exist in 1999, is included in steady state calculations.

Sweden: As for Italy, older workers are in the "old" pension system in 1999 but will be in the "new" one in the long run. Therefore, the results presented for current systems assume that all workers are in the new system. The latter is not actuarially neutral, while in the "old" system there was no implicit tax on continued work beyond age 60 because work could be fully combined with the receipt of a pension. Therefore, implicit tax rates are higher.

United Kingdom: the state earnings-related pension system (SERPS) was replaced by the State Second Pension in 2003.

United States: the standard retirement age is scheduled to rise from 65 to 67 over the period 2000-2022 and the actuarial adjustment for deferred retirement will be increased.

59. Finally, other planned reforms and changes in pension systems are not incorporated in steady state calculations, because it remains unclear at this stage to what extent they will be implemented in practice (indexation of the basic pension amount on prices instead of wages in the future in Canada and the United Kingdom) or what their impact on implicit tax rates will be (planned changes in Japan over the period 2013-2025 are not modelled). Also not included is the projected rise in the standard retirement age from 60 to 65 in Korea (as part of the 1998 reform). 


\section{Appendix 4: Theoretical relationship between replacement rates and implicit taxes on continued work}

60. The existence of a direct link between the magnitude of the implicit tax rate on continued work and the level of the replacement rate is rather intuitive: the higher the replacement rate, the higher the opportunity cost of continuing working, i.e., the higher the implicit tax on continued work, ceteris paribus. The calculations presented below establish this link more formally and show that it is in fact more complex than this simple intuition suggests. For clarity purposes, it is assumed by convention that $R=0$. In addition, the survival function is assumed to be computed from $\mathrm{R}$ to infinity and the mortality rate at each age is supposed to be constant and equal to $\mathrm{p}=\mathrm{p}_{\mathrm{A}}$. As shown above, these assumptions were not made when computing actual pension wealth levels, but they greatly simplify the demonstration. The level of pension wealth of an individual currently eligible to a pension can thus be written as:

$$
P W Y(0)=\sum_{A=0}^{\infty}\left(S_{A} * R_{A}\right) /(1+r)^{A}
$$

Where $R_{A}$ is the replacement rate and $S_{A}$ is the value of the survival function at age $A$.

Given the assumption of a constant mortality rate at each age, the survival function is:

$$
S_{A}=\prod_{i=1}^{i=A}(1-p) \approx \prod_{i=1}^{i=A} 1 /(1+p)^{i} \approx 1 /(1+p)^{A}
$$

Combining these two equations, and incorporating the fact that $R_{A}$ is constant $\left(R_{A}=R\right)$ because pensions are assumed to be indexed on prices, we obtain:

$$
P W Y_{0} \approx \sum_{A=0}^{\infty} R_{A} /(1+r+p)^{A} \approx R *[1+1 /(r+p)]
$$

Let us assume that pension rights accrue at rate a, so that $\mathrm{P}_{\mathrm{R}+1}=(1+\mathrm{a}) \mathrm{P}_{\mathrm{R}}$, and that no pension can be received before full retirement (i.e., there is a strict income test). The present value (i.e., at age $\mathrm{R}=0$ ) of the pension wealth of the individual if he defers the receipt of his pension by one year is:

$$
P W Y_{1} /(1+r+p) \approx \sum_{A=1}^{\infty}\left[R_{A} *(1+a) /(1+r+p)^{A-1}\right] /(1+r+p) \approx R *(1+a) /(r+p)
$$

The implicit tax on continuing working for one year is:

Implicit tax $=-\left[(1+r+p) * P W Y_{1}-P W Y_{0}-c\right]=R *[(r+p)(1+c)-a] /(r+p)$

This equation states that when $a<(r+p)(1+c)$, i.e., when the accrual rate is below the "actuarially neutral" level, there is an implicit tax on continued work whose magnitude is positively related to the level of the replacement rate.

\section{Appendix 5: Overview of the "option value" model of the retirement decision}

61. Standard lifetime retirement models have an important drawback: they implicitly assume that workers know with certainty the future values of all parameters (such as wage rates) influencing their retirement decision. Concomitant with this assumption, the life-cycle approach of retirement does not allow any updating of information as the individual ages. Given the degree of uncertainty surrounding the future values of these parameters, such behaviour is unlikely. 
62. Another approach to modelling retirement behaviour, fairly close in spirit to lifetime retirement models but better suited to incorporate uncertainty, has been proposed by Stock and Wise (1990) and has gained wide popularity in the literature over the past decade. These authors develop an "option value" model based on Lazear's intuition (1979) that by delaying retirement, individuals retain the option to retire at a later date under potentially more advantageous terms. To fit with observed reality, retirement is described as an absorbing rather than as a dynamic state, i.e., it is assumed ex-ante that the transition to retirement is abrupt and irreversible. At any given age, it is assumed that a working individual compares (in utility terms) the expected present value of retiring immediately with the value of retiring at each future age until expected death. The maximum of the difference in expected present values of retiring at each future age versus immediate retirement is called the option value of postponing retirement. As long as this option value is positive, the person continues to work, because there exists at least one future date of retirement for which the present value of retiring exceeds that of immediate retirement; otherwise he/she retires.

63. More formally, let us assume that an employee currently aged $\mathrm{R}=0$ (by convention) has to make a decision upon his future retirement age $R>=0$. Let $V_{0}(R)$ be the expected present value of retiring at age R. $V_{0}(R)$ is equal to the expected present value of future utilities of the stream of income (discounted to current age), which is the sum of two components: $i$ ) the expected present value of future utilities of the stream of wages earned from 0 to (R-1); and, ii) the expected present value of future utilities of the stream of retirement benefits received from $\mathrm{R}$ until the expected age of death. The gain, evaluated at current age, from postponing retirement until age $\mathrm{R}$ is given by:

$\mathrm{G}_{0}(\mathrm{R})=\mathrm{E}_{0}\left[\mathrm{~V}_{0}(\mathrm{R})\right]-\mathrm{E}_{0}\left[\mathrm{~V}_{0}(0)\right]$

Letting $\mathrm{R}^{*}$ be the age providing the maximum gain, the option value of postponing retirement (or the opportunity cost of retiring) is $\mathrm{G}_{0}\left(\mathrm{R}^{*}\right)=\mathrm{E}_{0}\left[\mathrm{~V}_{0}\left(\mathrm{R}^{*}\right)\right]-\mathrm{E}_{0}\left[\mathrm{~V}_{0}(0)\right]$. So long as there is a future retirement date $\mathrm{R}^{*}>0$ such that $\mathrm{G}_{0}\left(\mathrm{R}^{*}\right)>0$, the employee will postpone retirement. He/she retires when $\mathrm{G}_{0}\left(\mathrm{R}^{*}\right)<0$, i.e., when $\mathrm{E}_{0}\left[\mathrm{~V}_{0}(\mathrm{R})\right]<\mathrm{E}_{0}\left[\mathrm{~V}_{0}(0)\right]$ for all $\mathrm{R}>0$.

64. In addition to its ability to incorporate uncertainty surrounding the many variables influencing retirement behaviour, a major appeal of this approach is that it allows a very straightforward treatment of the influence of institutional factors. Indeed, the structure of pension and tax systems directly affects the retirement decision via the option value. For instance, high labour taxes or high taxes on continued work beyond a certain age tend to lower the option value of postponing retirement and reduce the retirement date, ceteris paribus. Accordingly, an unexpected decline in the wage rate unparalleled by a downward revision to future retirement benefits may lower the option value of continuing to work and induce earlier retirement. 
ECO/WKP(2003)24

Table 1. Standard and early ages of entitlement to old-age pension benefits

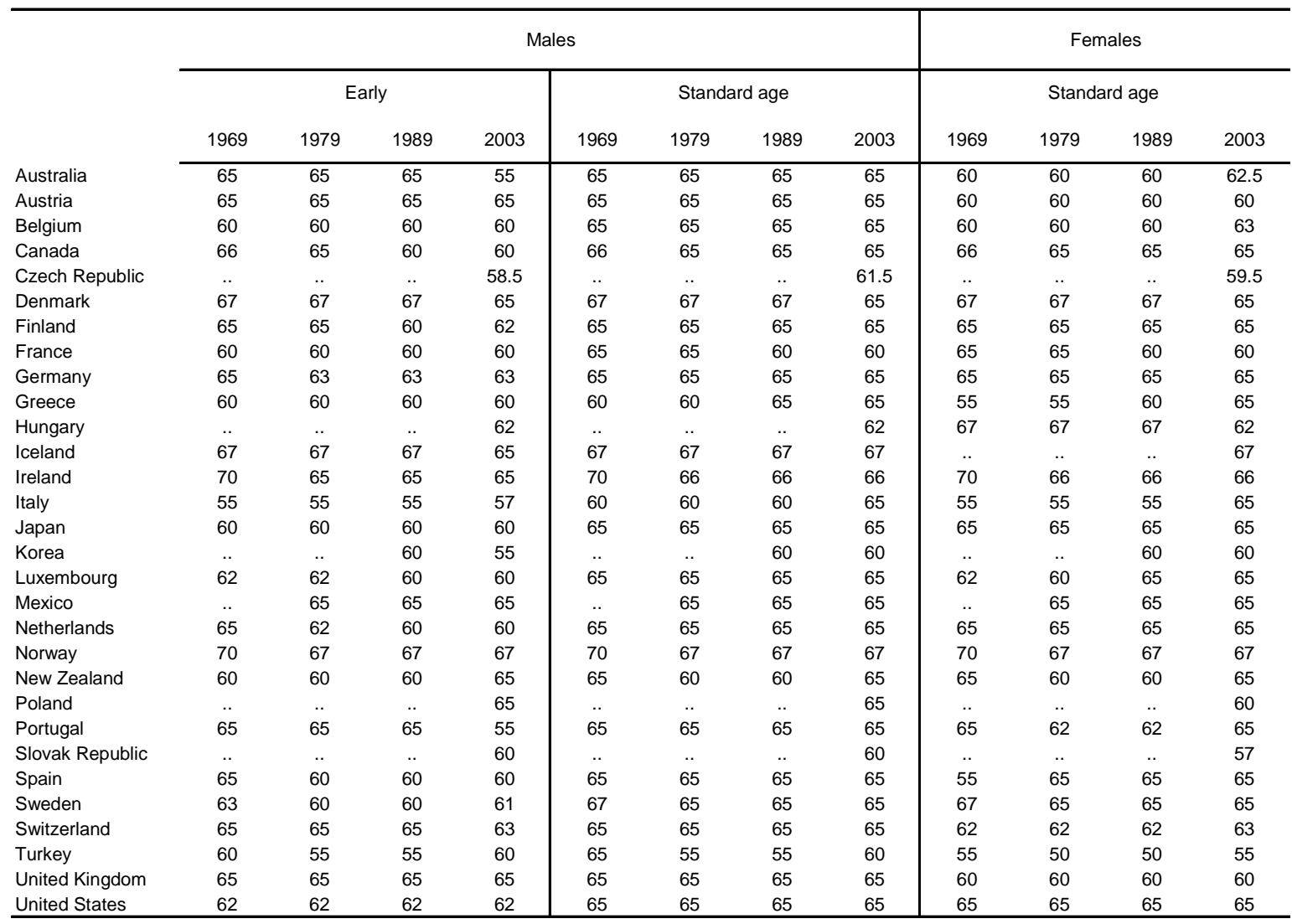

Notes:

Australia: minimum retirement age (i.e. at which superannuation savings can be drawn) will increase to 60 over the period $2015-2025$. standard age for women to be increased from age 62.5 to age 65 between 2003 and 2013.

Austria : early age of eligibility does not incorporate special early retirement for long insurance years, which will be progressively phased out (following the 2003 reform) but could still be accessed from age 61.5 in 2003 (60 in 1969, 1979 and 1989). Standard age for women to be increased from age 60 to age 65 between 2024 and 2033.

Belgium: standard age for women scheduled to rise to age 65 by 2009.

Czech Republic: standard and minimum retirement ages are scheduled to rise gradually to reach age 62 for men and age 61 for women (with no children) in 2007.

Greece: standard age is 62 for men and 57 for women who first started to work before 1992

Iceland: early retirement age in 2003 is still 67 for the basic pension. However most occupational pension schemes, which are progressively maturing, set the minimum retirement age at 65 .

Italy: minimum retirement age is the minimum age of eligibility to a seniority pension, also equal to the minimum retirement age in the new pension system. Standard age is 60 (instead of 65) for women who first started to work before 1996

Korea: standard age scheduled to rise from age 60 to age 65 between 2011 and 2033.

Luxembourg: early age of eligibility does not incorporate the special early retirement scheme ("pré-retraite"), which can be accessed from age 57 with 40 years of contribution.

Norway: early age of eligibility does not incorporate the special early retirement (AFP) scheme, which can be accessed from age 62 in 2003.

Poland: standard age is 55 for women with 30 years of insurance.

Slovak republic: standard age for women varies between 53 and 57 according to number of children raised.

Switzerland: standard age for women will be 64 in 2005.

Turkey: standard age is 55 for men and 50 for women who first started to work before 1990 .

United Kingdom: standard age for women will rise from age 60 to age 65 over 2010-2020 period.

United States: standard age for both men and women scheduled to rise to age 67 over 2000-2022 period.

Source: U.S. Department of Health and Human Services, Social Security Programs Throughout the World, various issues 


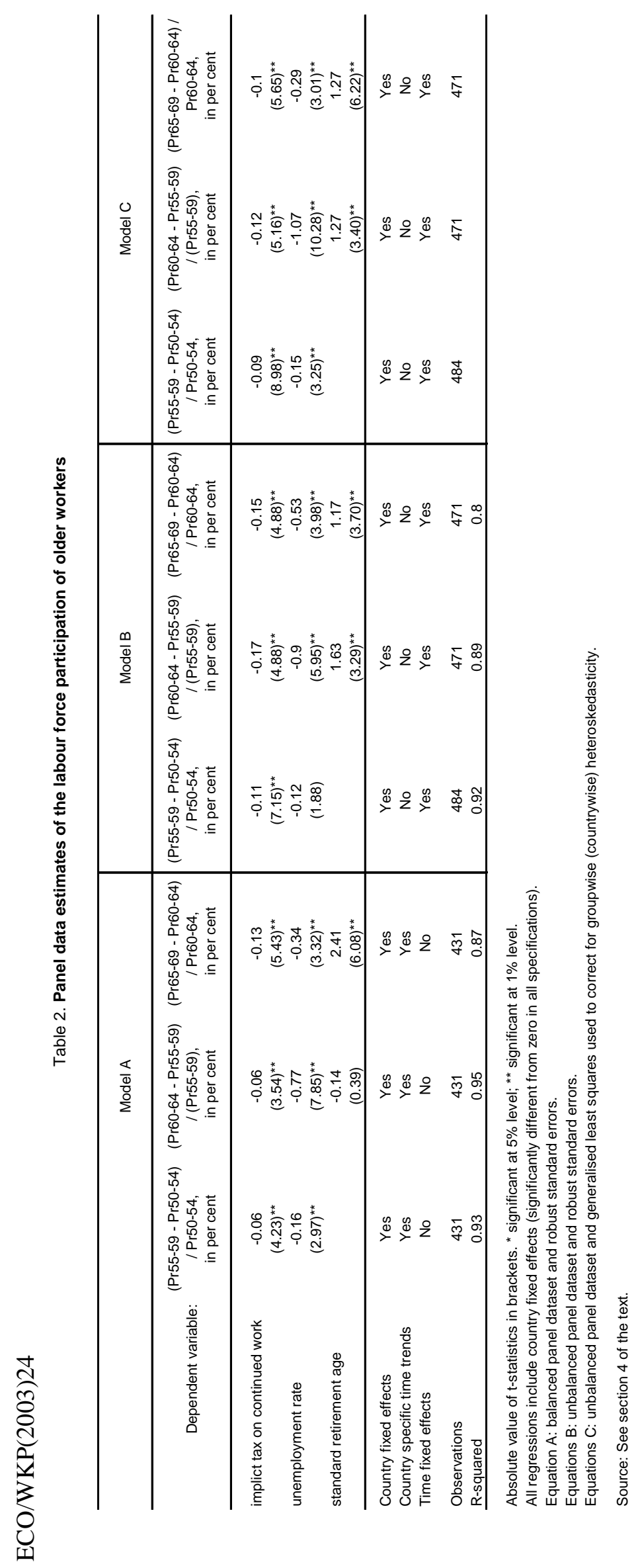

i 
Figure 1. Labour force participation of older workers and estimated effective retirement age in 2000

Men

Effective retirement age, 2000

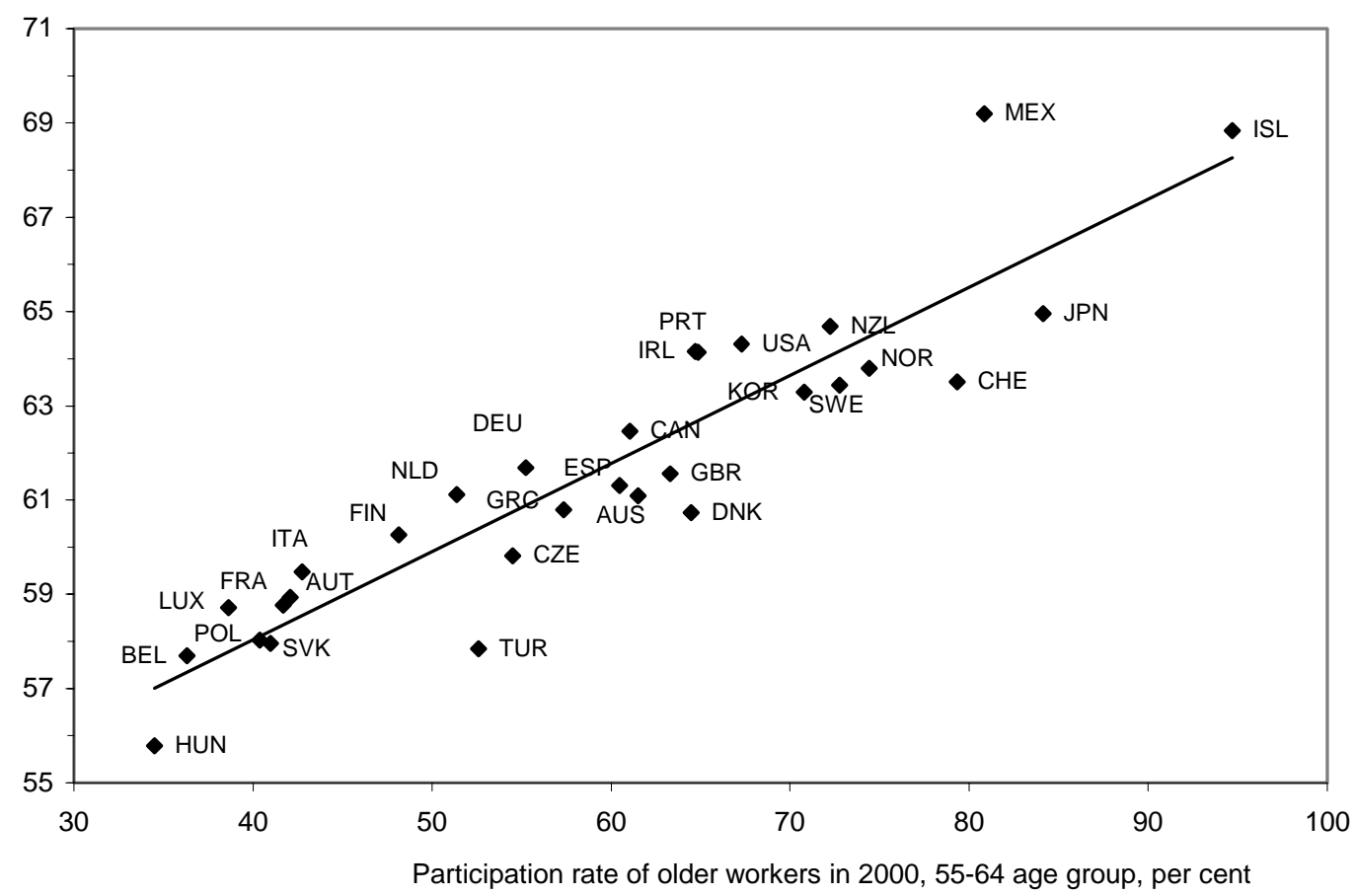

Correlation coefficient: $\quad 0.92$ **

** significant at the $1 \%$ level.

Sources: Labour Force Statistics (Part III) and Burniaux et al. (2003). 


\section{ECO/WKP(2003)24}

Figure 2. Average expected replacement rates over next 5 years in current old-age pension systems, average across 6 situations ( 3 earnings levels and 2 marital statuses)

In per cent $\quad$ At age 60

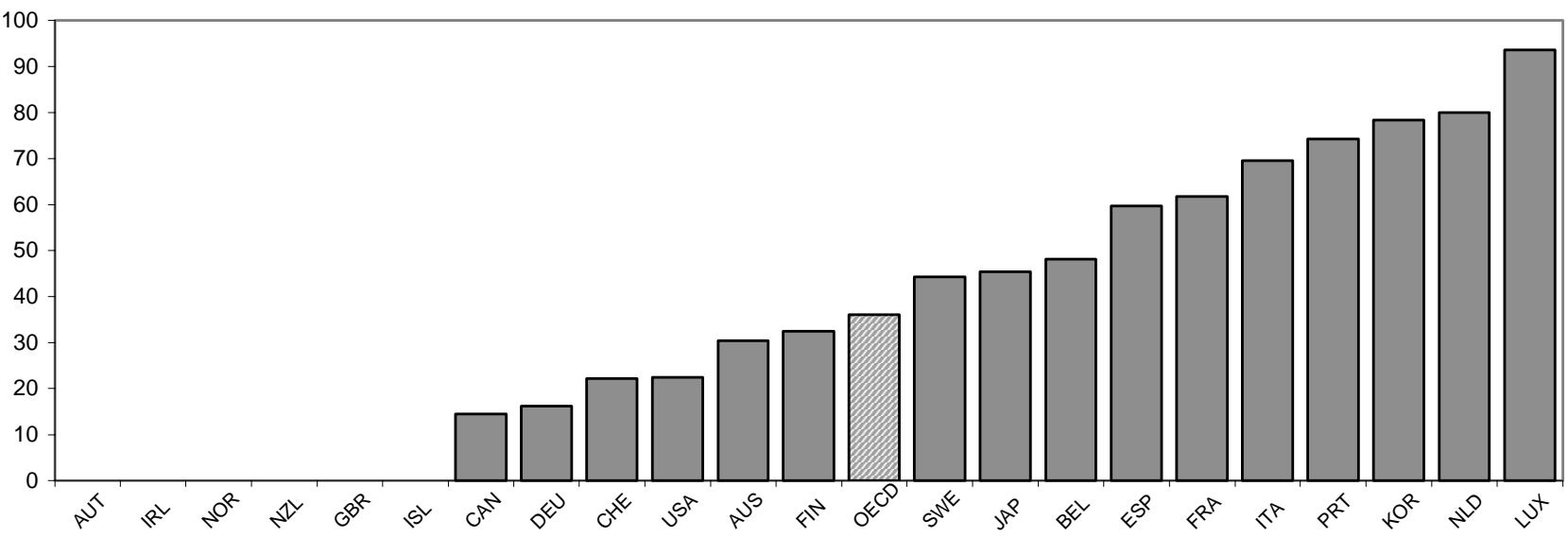

In per cent At age 65

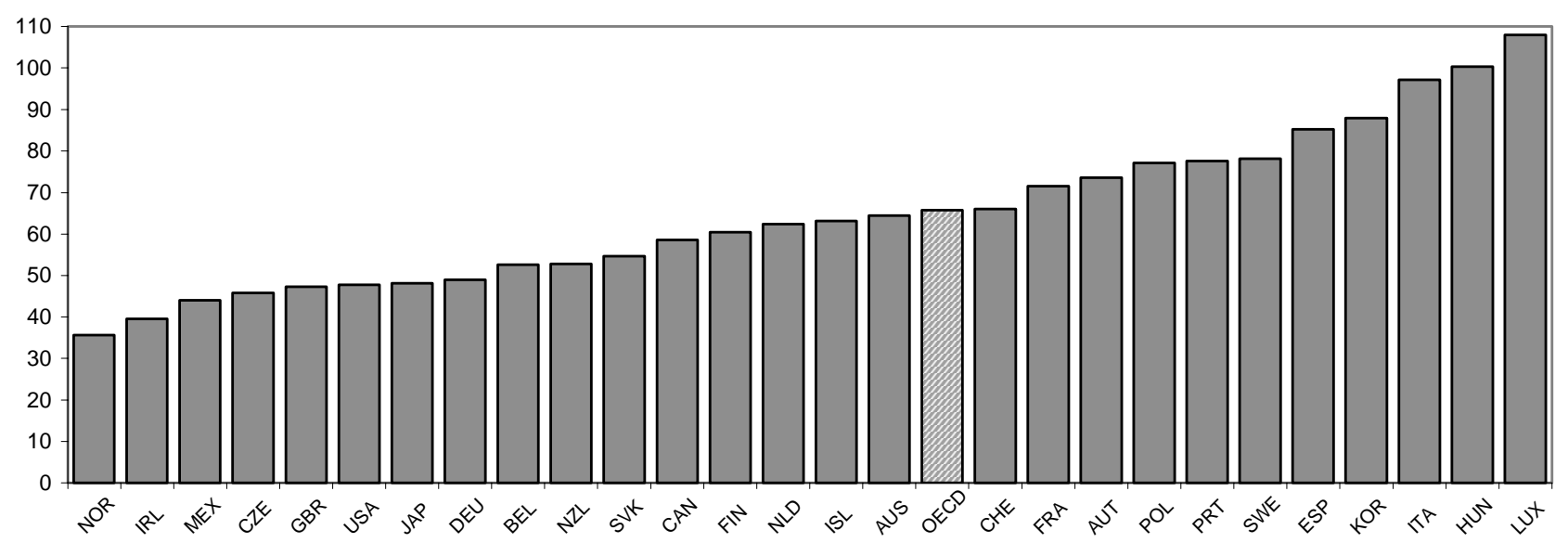

For the Netherlands, the calculations at age 60 is based on a "typical" VUT scheme.

For Czech Republic, Hungary, Mexico, Poland and Slovak Republic, the calculations are done only at age 65 for a single worker with average earnings.

Source: See Section 2 and Appendix 1 of the text. 
Figure 3. Historical changes in average expected replacement rates in old-age pension systems, average across 6 situations ( 3 earnings levels and 2 marital statuses)

At age 60

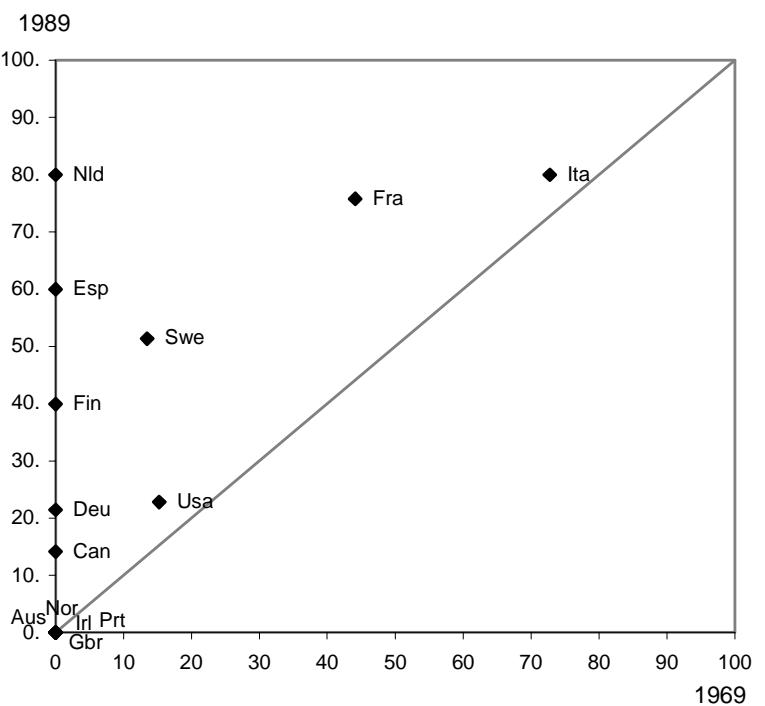

current systems

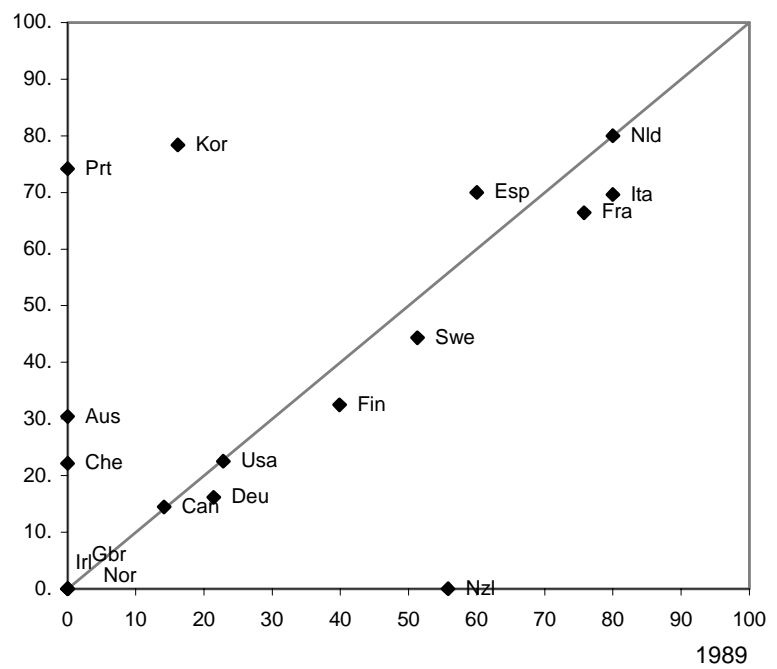

At age 65

1989

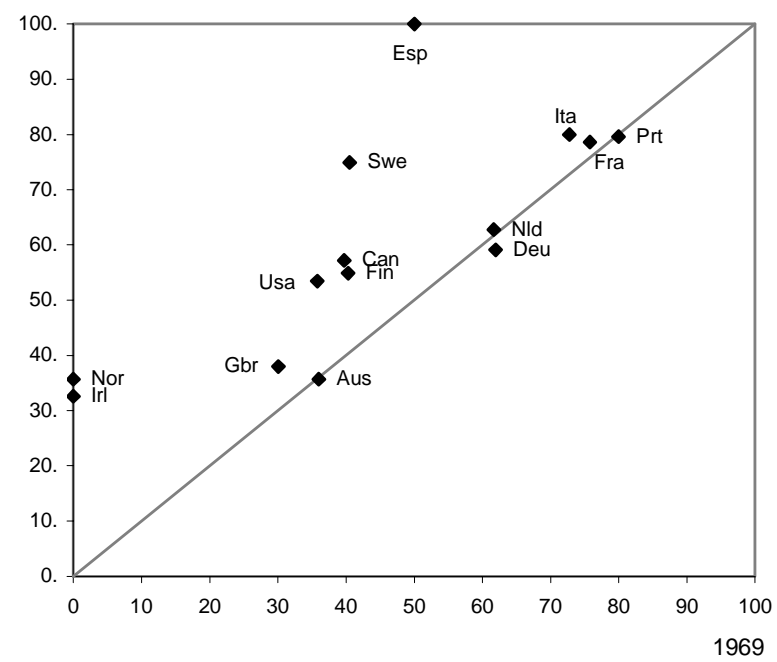

current systems

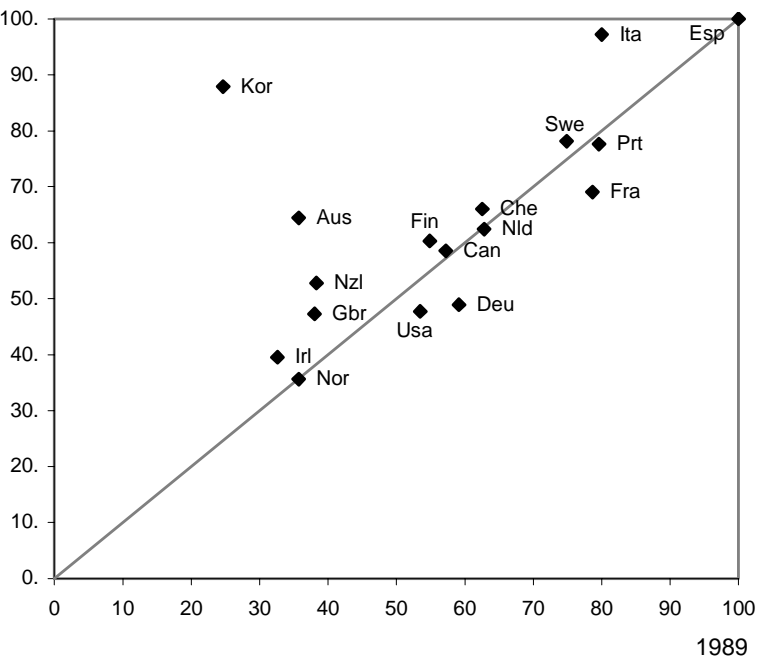

Source: See Section 2 and Appendix 1 of the text. 


\section{ECO/WKP(2003)24}

Figure 4. Average implicit tax rates on continued work over next 5 years in current old-age pension systems, single worker with average production worker (APW) earnings

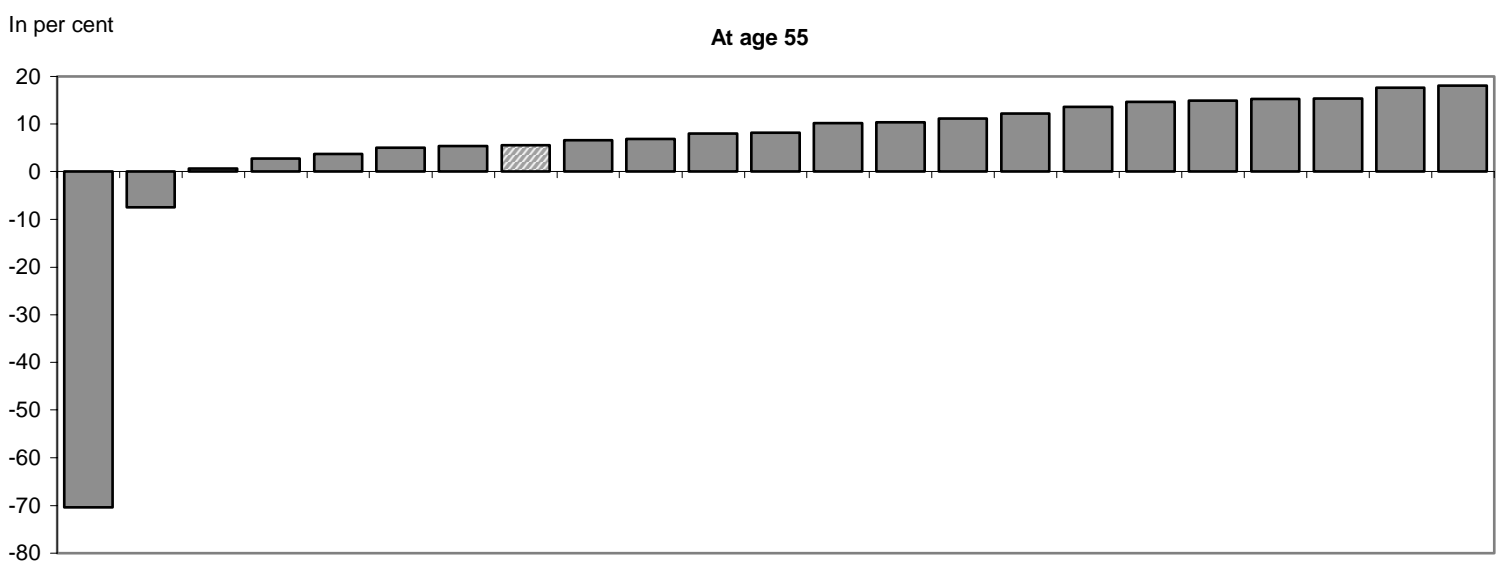

LUX FRA NZL ITA KOR USA ISL OECD JAP CAN SWE BEL AUT DEU GBR FIN NLD PRT IRL NOR AUS ESP CHE

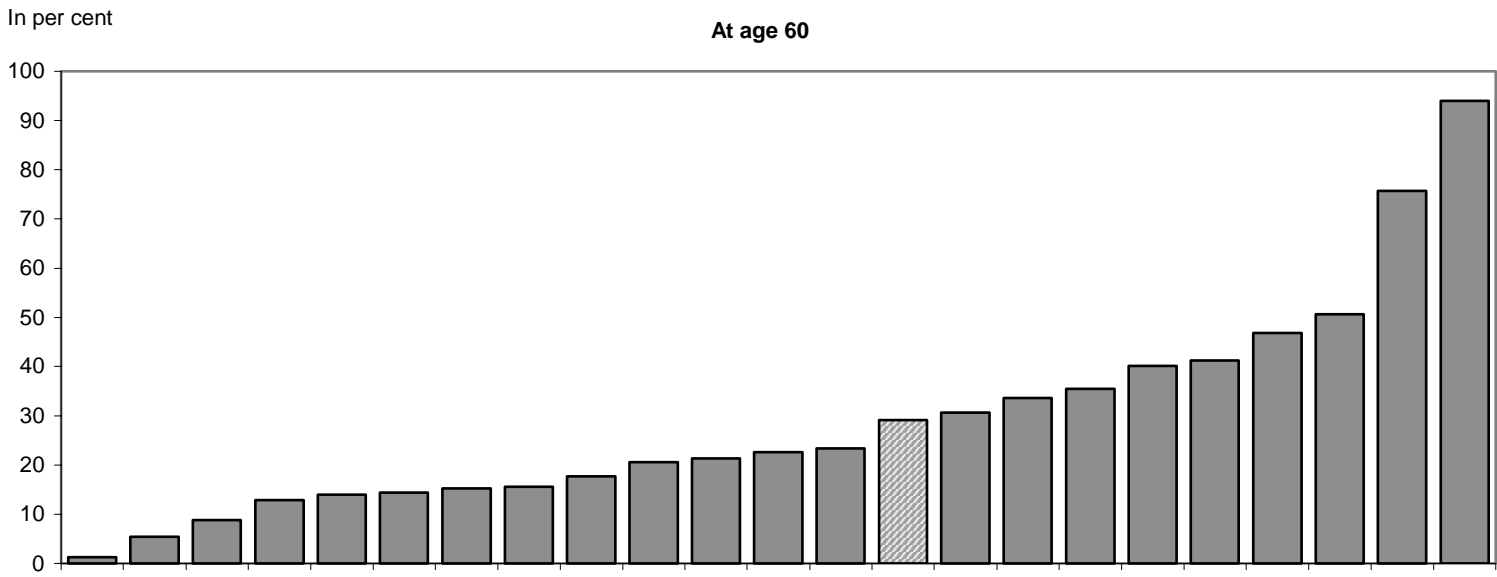

NZL ISL AUT USA GBR PRT IRL CAN DEU ITA NOR CHE AUS OECD FIN ESP SWE JAP KOR BEL FRA LUX NLD

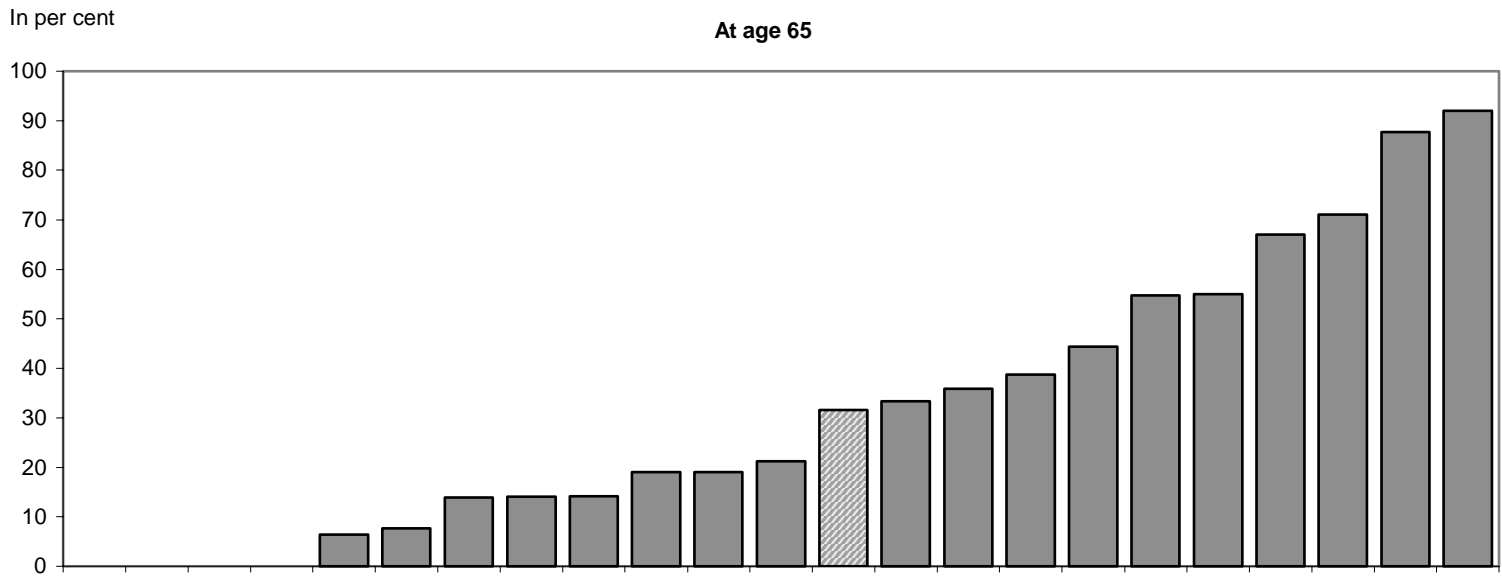

DEU LUX NLD NZL CAN IRL USA PRT JAP ISL CHE GBR OECD AUS KOR NOR SWE BEL FIN AUT FRA ITA ESP

Source: See Section 2 and Appendix 2 of the text. 
Figure 5. Average expected replacement rates and implicit tax rates on continued work in current old-age pension systems

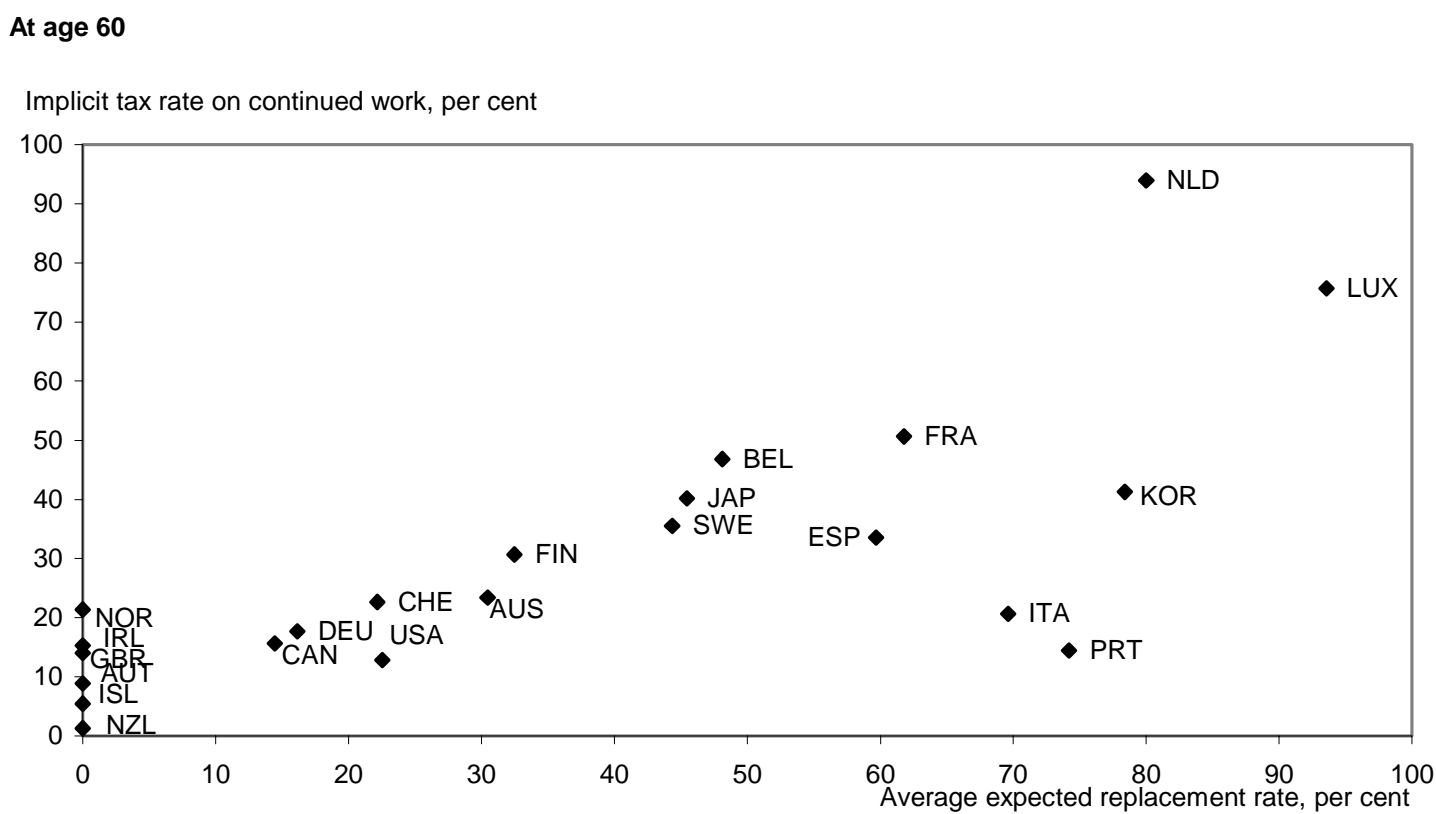

Correlation: $\quad 0.75$

\section{At age 65}

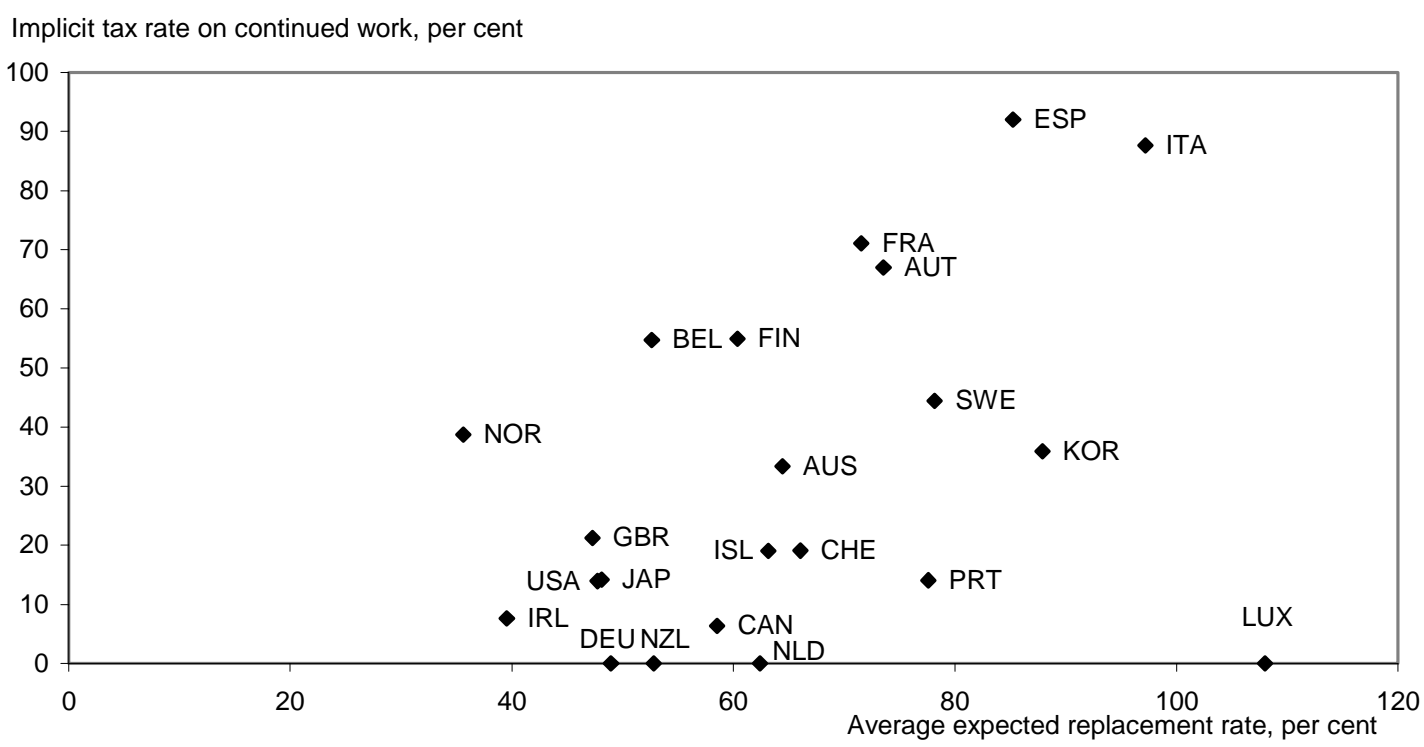

Correlation: $\quad 0.37$

Source: See Section 2 and Appendixes 1 and 2 of the text. 


\section{ECO/WKP(2003)24}

Figure 6. Historical changes in average implicit tax rates on continued work in old-age pension systems, single worker with APW earnings

At age 60

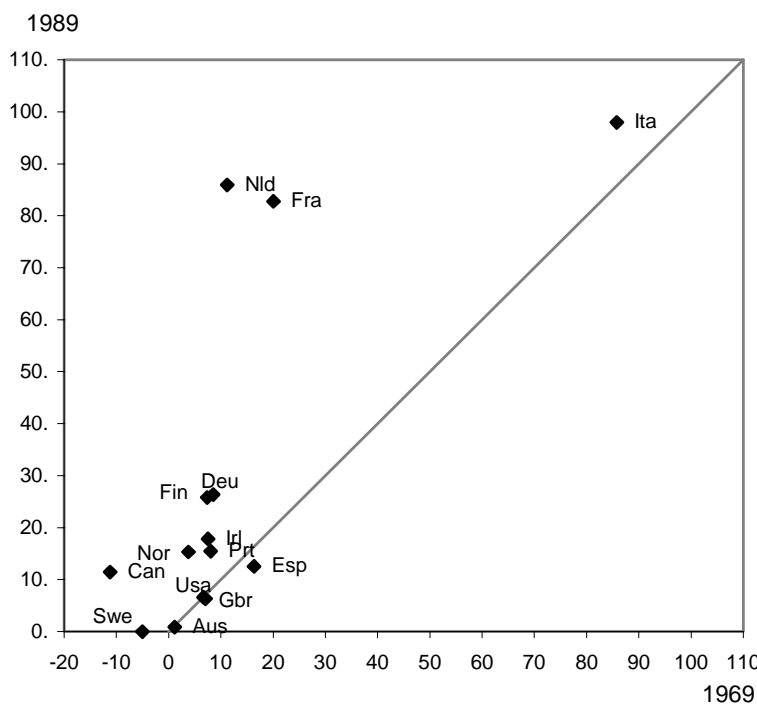

current systems

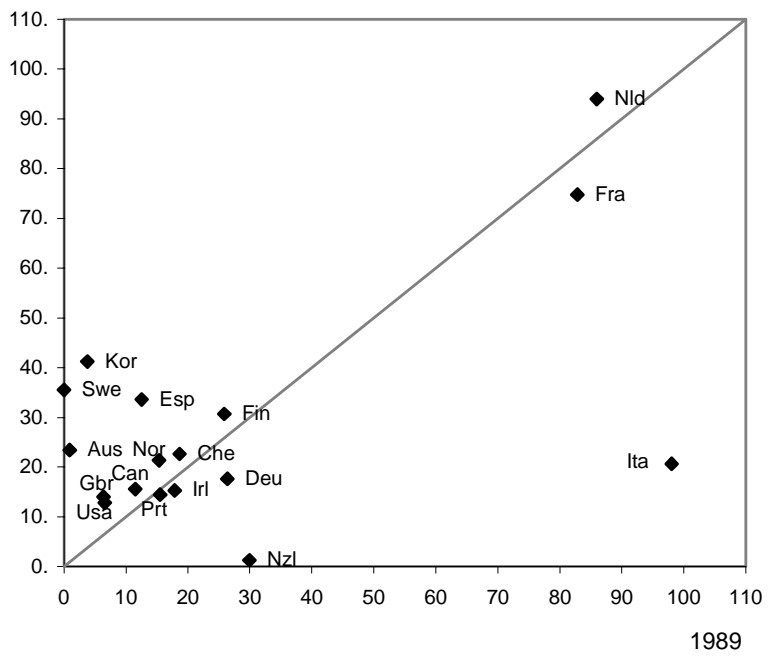

At age 65

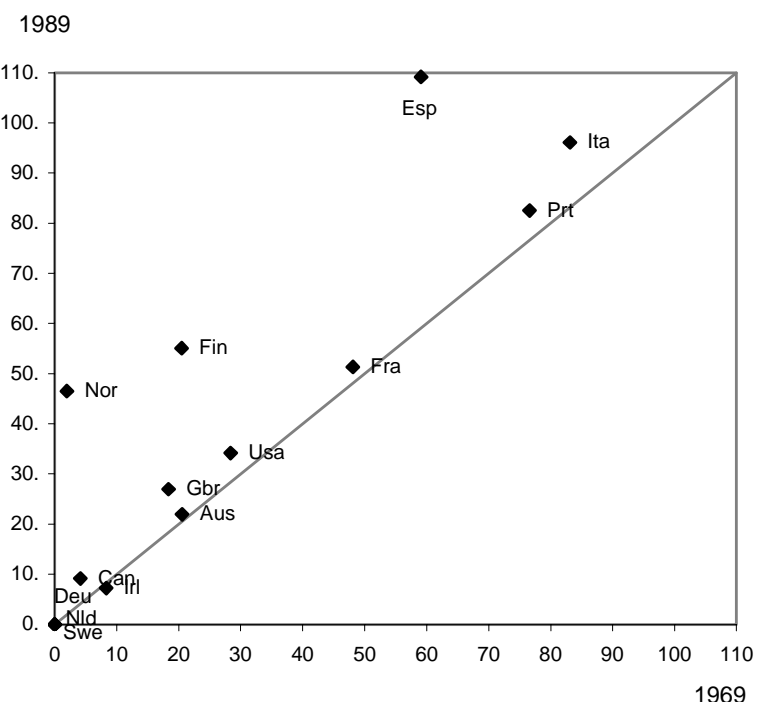

current systems

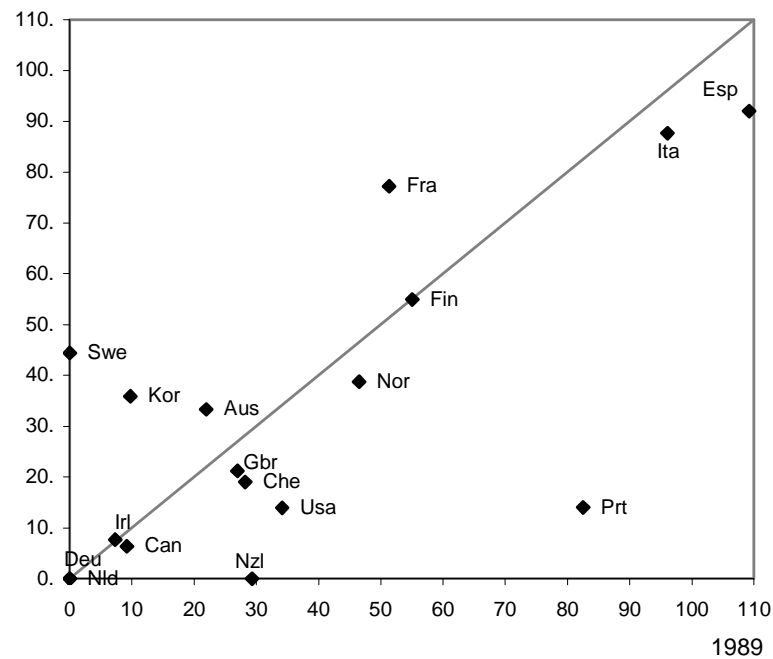

Source: See Section 2 and Appendix 2 of the text. 
ECO/WKP(2003)24

Figure 7. Fall in male labour force participation between 50-54 and 55-59 and implicit tax rates on continued work (single worker APW earnings, 1999)

Panel A.

Percentage change in labour force participation between $50-54$ and $55-59^{1}$

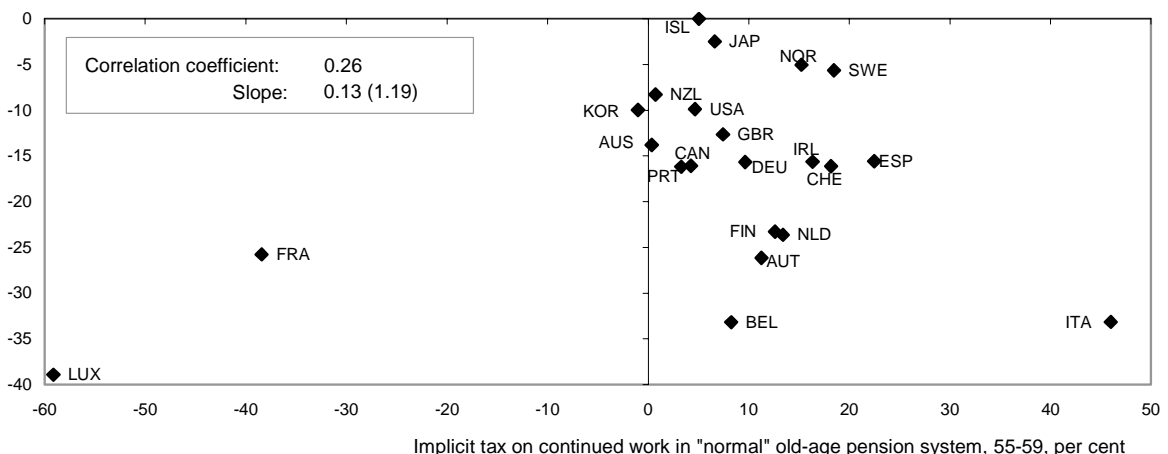

Panel B.

Percentage change in labour force participation between 50-54 and 55-59 ${ }^{1}$

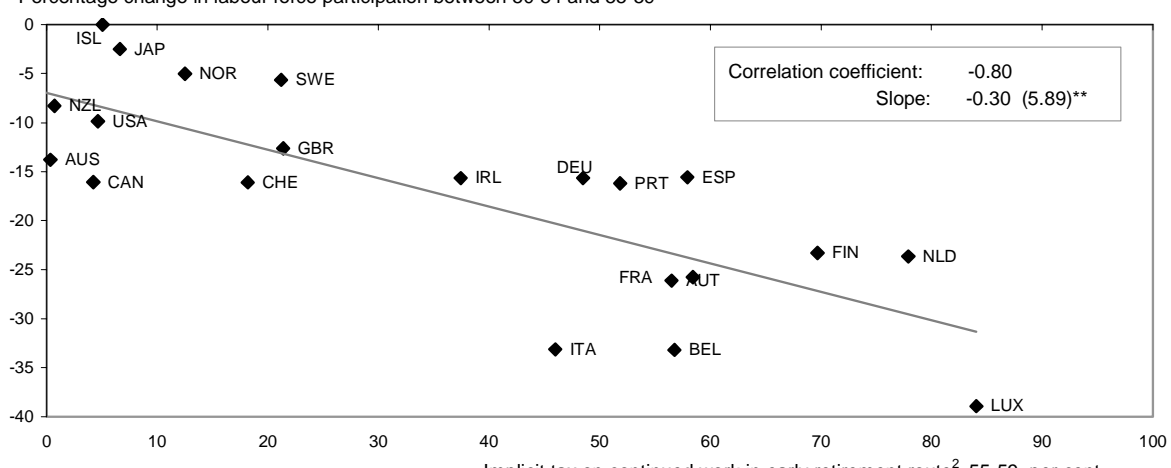

Panel C.

Percentage change in labour force participation between 50-54 and $55-59^{1}$

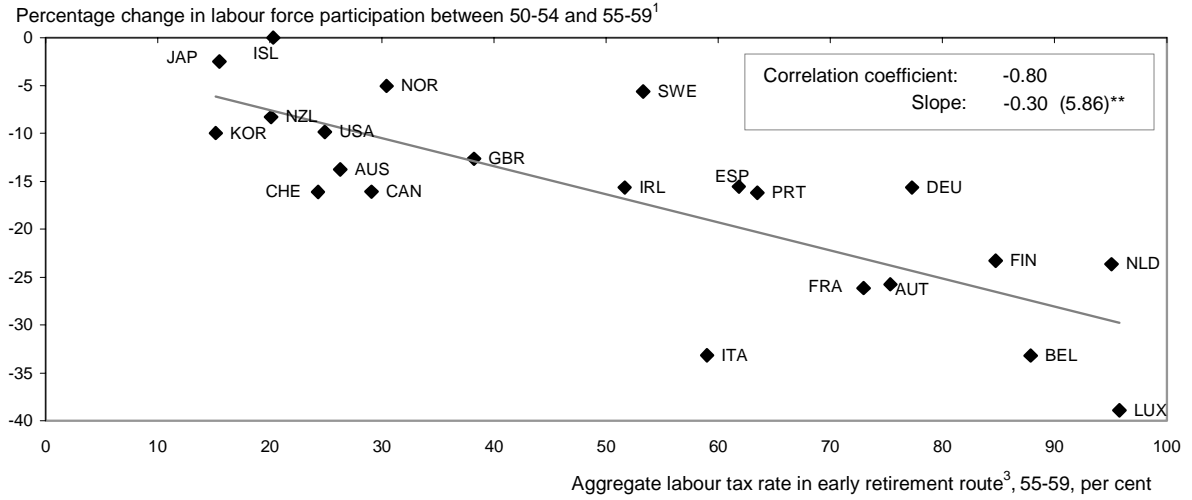

t-statistic in brackets. *: significant at $5 \%$ level, ** significant at $1 \%$ level.

1. (Pr55-59 - Pr50-54)/Pr50-54, per cent.

2. The early retirement route is modelled as the unemployment benefits / assistance pathway into retirement with the

exception of Ireland, where the modelling refers to the pre-retirement allowance, and Luxembourg, where disability

benefits were considered given their widespread incidence among pensioners. In those countries where it was

considered that no early retirement scheme could be widely used to withdraw from the labour market before

the minimum pensionable age (Australia, Canada, Iceland, Italy, Japan, Korea, New Zealand, Norway, Sweden,

Switzerland and United States) the retirement scheme considered in the chart is simply the "regular" old-age pension system.

3. The aggregate labour tax rate is computed as the sum of two components: the usual labour tax wedge; the implicit tax on

continued work in the early retirement route (less the rate of contribution to the old-age pension system so as to eliminate double counting) expressed as a percentage of total labour cost.

Source: See Section 3 of the text. 


\section{ECO/WKP(2003)24}

Figure 8. Fall in male labour force participation between 55-59 and 60-64 and implicit tax rates on continued work (single worker APW earnings, 1999)

Panel A.

Percentage change in labour force participation between $55-59$ and $60-64^{1}$

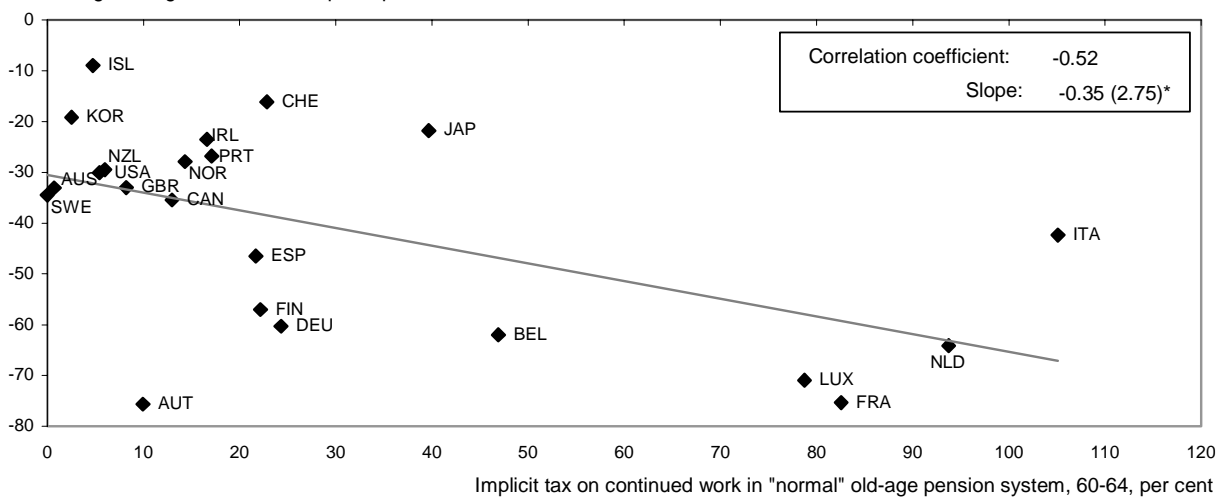

Panel B.

Percentage change in labour force participation between $55-59$ and $60-64^{1}$

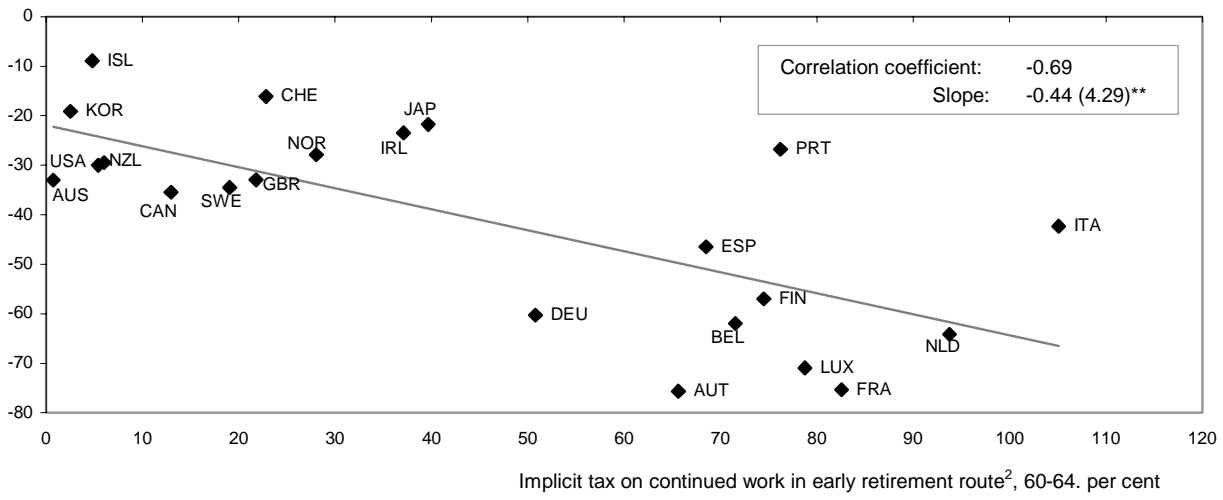

Panel C.

Percentage change in labour force participation between 55-59 and 60-64 ${ }^{1}$

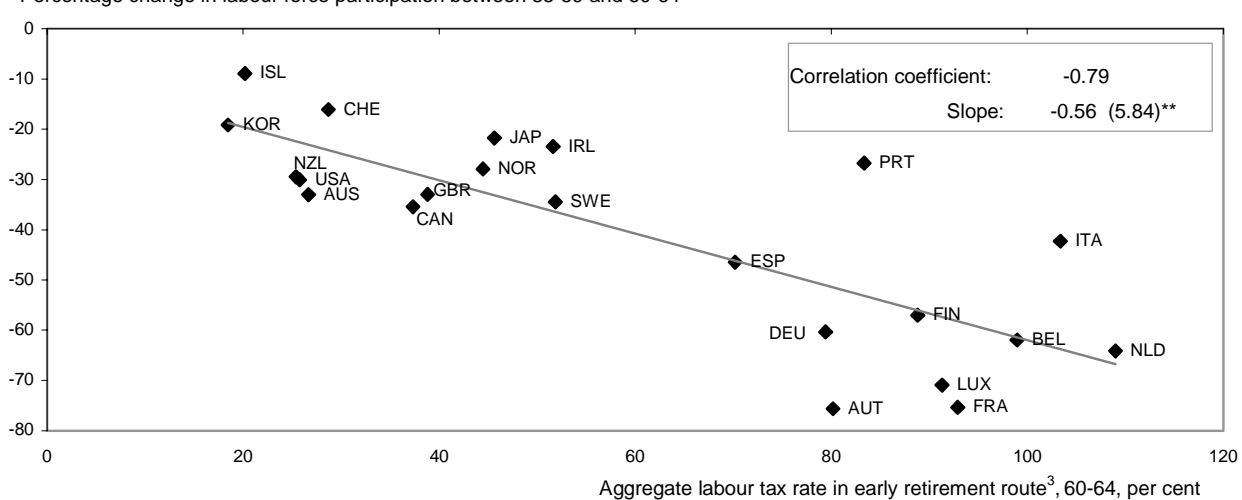

t-statistic in brackets. *: significant at $5 \%$ level, ${ }^{*}$ significant at $1 \%$ level.

1. (Pr60-64 - Pr55-59) / Pr55-59, per cent

2. The early retirement route is modelled as the unemployment benefits / assistance pathway into retirement with the

exception of Ireland, where the modelling refers to the pre-retirement allowance, and Luxembourg, where disability

benefits were considered given their widespread incidence among pensioners. In those countries where it was

considered that no early retirement scheme could be widely used to withdraw from the labour market before

the minimum pensionable age (Australia, Canada, Iceland, Italy, Japan, Korea, New Zealand, Norway, Sweden,

Switzerland and United States) the retirement scheme considered in the chart is simply the "regular" old-age pension system.

3. The aggregate labour tax rate is computed as the sum of two components: the usual labour tax wedge; the implicit tax on

continued work in the early retirement route (less the rate of contribution to the old-age pension system so as to eliminate double

counting) expressed as a percentage of total labour cost.

Source: See Section 3 of the text. 


\section{WORKING PAPERS}

The full series of Economics Department Working Papers can be consulted at www.oecd.org/eco/Working_Papers/

369. Policies for an Ageing Society: Recent Measures and Areas for Further Reform

(November 2003) Bernard Casey, Howard Oxley, Edward Whitehouse, Pablo Antolin, Romain Duval, Willi Leibfritz

368. Financial Market Integration in the Euro Area (October 2003) Carl Gjersem

367. Recent and Prospective Trends in Real Long-Term Interest Rates: Fiscal Policy and Other Drivers (September 2003) Anne-Marie Brook

366. Consolidating Germany's finances: Issues in public sector spending reform (September 2003) Eckhard Wurzel

365. Corporate Taxation of Foreign Direct Investment Income 1991-2001 (August 20030) Kwang-Yeol Yoo

364. Indicator Models of Real GDP Growth in Selected OECD Countries (July 2003) Franck Sédillot and Nigel Pain

363. Post-Crisis Change in Banking and Corporate Landscapes - the Case of Thailand (July 2003) Margit Molnar

362. Post-Crisis Changes in Banking and Corporate Landscapes in Dynamic Asia (June 2003) Margit Molnar

361. After The Telecommunications Bubble (June 2003) by Patrick Lenain and Sam Paltridge

360. Controlling Public Spending in Iceland (June 2003) Hannes Suppanz

359. Policies and International Integration: Influences on Trade and Foreign Direct Investment (June 2003) Giuseppe Nicoletti, Steve Golub, Dana Hajkova, Daniel Mirza, Kwang-Yeol Yoo

358. Enhancing the Effectiveness of Public Spending in Finland (June 2003) Philip Hemmings, David Turner and Seija Parviainen

357. Measures of Restrictions on Inward Foreign Direct Investment for OECD Countries (May 2003) Stephen S. Golub

356. Tax Incentives and House Price Volatility in the Euro Area: Theory and Evidence (May 2003) Paul van den Noord

355. Structural Policies and Growth: A Non-technical Overview (May 2003) Alain de Serres

354. Tax Reform in Belgium (May 2003) David Carey

353. Macroeconomic Policy and Economic Performance (April 2003) Pedro de Lima, Alain de Serres and Mike Kennedy 


\section{ECO/WKP(2003)24}

352. Regulation and Investment

(March 2003) Alberto Alesina, Silvia Ardagna, Giuseppe Nicoletti and Fabio Schiantarelli

351. Discretionary Fiscal Policy and Elections: The Experience of the Early Years of EMU

(March 2003) Marco Buti and Paul van den Noord

350. The US Health System: An Assessment and Prospective Directions for Reform (February 2003) Elizabeth Docteur, Hannes Suppanz and Jaejoon Woo

349. The Effectiveness of Public Expenditure in Portugal (February 2003) Chiara Bronchi

348. Comparative Analysis of Firm Demographics and Survival: Micro-Level Evidence for the OECD Countries (February 2003) Eric Bartelsman, Stefano Scarpetta and Fabiano Schivardi

347. Regulation, Productivity and Growth: OECD Evidence (January 2003) Giuseppe Nicoletti and Stefano Scarpetta

346. Public Expenditure Management in Poland

(December 2002) Andrew Burns and Kwang-Yeol Yoo

345. Enhancing the Effectiveness of Public Expenditure in Sweden (December 2002) Deborah Roseveare

344. The Decline in Private Saving Rates in the 1990s in OECD Countries: How Much Can Be Explained by NonWealth Determinants

(November 2002) Alain de Serres and Florian Pelgrin

343. Enhancing the Effectiveness of Public Expenditure in Norway (October 2002) Isabelle Joumard and Wim Suyker

342. Productivity and Convergence in a Panel of OECD Countries: Do Regulations and Institutions Matter? (September 2002) Stefano Scarpetta and Thierry Tressel

341. Managing Public Expenditure: The UK Approach (August 2002) Paul van den Noord

340. The Brazilian Pension System: Recent Reforms and Challenges Ahead (August 2002) Marcos Bonturi

339. Challenges in the Mexican Financial Sector (August 2002) Marcos Bonturi

338. Coping with Population Ageing in Hungary (August 2002) Andrew Burns and Jaromir Cekota

337. Next Steps for Public Spending in New Zealand: The Pursuit of Effectiveness (July 2002) Dave Rae

336. Strengthening the Management of Public Spending in Hungary (July 2002) Jaromir Cekota, Rauf Gonenc and Kwang-Yeol Yoo

335. Automatic Stabilisers and Market Flexibility in EMU: Is There a Trade-Off? (July 2002) Marco Buti, Carlos Martinez-Mongay, Khalid Sekkat and Paul van den Noord

334. The Economic Consequences of Terrorism (July 2002) Patrick Lenain, Marcos Bonturi and Vincent Koen 